\title{
The Wage-Productivity Gap Revisited: Is the Labour Share Neutral to Employment?*
}

\author{
Marika Karanassou \\ Queen Mary, University of London ${ }^{\dagger}$ \\ and IZA
}

\section{Hector Sala}

Universitat Autònoma de

Barcelona and IZA

12 July 2010

\begin{abstract}
This paper challenges the prevailing view of the neutrality of the labour income share to labour demand, and investigates its impact on the evolution of employment. Whilst maintaining the assumption of a unitary long-run elasticity of wages with respect to productivity, we demonstrate that productivity growth affects the labour share in the long run due to frictional growth (that is, the interplay of wage dynamics and productivity growth). In the light of this result, we consider a stylised labour demand equation and show that the labour share is a driving force of employment. We substantiate our analytical exposition by providing empirical models of wage setting and employment equations for France, Germany, Italy, Japan, Spain, the UK, and the US over the 1960-2008 period. Our findings show that the timevarying labour share of these countries has significantly influenced their employment trajectories across decades. This indicates that the evolution of the labour income share (or, equivalently, the wage-productivity gap) deserves the attention of policy makers.
\end{abstract}

JEL Classification: E24, E25, O47.

Keywords: Wages, productivity, labour income share, employment.

*Acknowledgments: This paper was completed while Hector Sala was visiting Cornell University School of Industrial and Labor Relations. Their warm hospitality is gratefully acknowledged. We are grateful to the Spanish Ministry of Science and Innovation for financial support through grant ECO200907636 .

${ }^{\dagger}$ School of Economics and Finance, Queen Mary, University of London, Mile End Road, London E1 4NS, UK; tel.: + (0)20 7882-8829; email: m.karanassou@qmul.ac.uk

${ }^{\ddagger}$ Department d’Economia Aplicada, Universitat Autònoma de Barcelona, Edifici B, 08193 Bellaterra, Spain; tel: +34-93.581.27.79; email: hector.sala@uab.es. 


\section{Introduction}

Macro-labour models often assume equal shifts in labour demand and wage setting in response to productivity changes, and embrace the notion that productivity gains are fully translated into wage rises that offset employment creation. Conventional wisdom asserts that if the long-run elasticity of wages with respect to labour productivity is unity, the labour income share is constant in the steady state and, thus, neutral to the performance of labour markets. (Hereafter, productivity refers to labour productivity.)

Contrary to the above, in this paper we argue that productivity growth determines the labour income share in the long run, and the labour share is a driving force of labour demand. This is a result of frictional growth, a phenomenon generated by the interplay of labour market frictions and growth.

In the context of our analysis it is important to acknowledge that the labour income share, since it can be expressed as the ratio of average real wage and productivity, is equivalent to the wage-productivity gap: ${ }^{1}$

$$
\text { labour share } \equiv \frac{\text { wages }}{\text { GDP }}=\frac{\text { wages } / \text { employees }}{\text { GDP/employees }}=\frac{\text { avg. wage }}{\text { productivity }} \equiv \text { wage gap. }
$$

If, say, a $10 \%$ productivity gain is accompanied by a $10 \%$ growth in the average real wage, then the wage gap is zero. However, the lower the wage growth, the more wages trail productivity gains and thus the higher is the wage gap.

Although the idea that productivity slowdowns decrease employment because they widen the gap between the real wage and productivity has been revived in recent years (e.g. Ball and Mankiw, 2002, Ball and Moffitt, 2002, Hatton, 2007), the contribution of this study is to show that a permanent increase in the growth rate of productivity has permanent (rather than transitory) effects on employment due to frictional growth. The interplay of lags and growth in the wage setting process implies that the growth of "wage aspirations' does not eventually catch up with productivity growth.

This contribution has a twofold dimension. First, whilst maintaining the assumption of a unitary long-run elasticity of wages with respect to productivity, we show that in a dynamic wage-setting equation with growing variables productivity growth affects wages in the long run. Second, in the light of this result (i.e. that the wage gap depends negatively on productivity growth), we consider a stylised labour demand equation and demonstrate that one implication of frictional growth is that the labour share (or wage gap) affects employment at all time horizons. This is shown analytically in Section 3 and subsequently quantified empirically.

In several studies of the OECD economies, the relatively high labour shares and un-

\footnotetext{
${ }^{1}$ Further, note the intricate association of the labour share to the (real) unit labour cost; the latter is defined as the average (real) cost of labour per unit of real output.
} 
employment rates witnessed in the 1970 s were attributed to wage demands which were perceived to be higher than the wage warranted by productivity growth. ${ }^{2}$ In this strand of literature, 'real wage rigidity' refers to the reluctance of workers to match a slowdown in productivity with a slowdown in actual wages. Under the widely accepted view that the growth of real wages is driven by the growth of productivity in the long run, a mismatch between wage aspirations and productivity growth violates fundamentals and thus leads to higher unemployment.

However, to argue that workers have been demanding too high wages after the end of the 1970 s would be a mere contradiction of reality. As Ball and Mankiw (2002, p. 129-130) put it "This story received attention in the early 1980s and then faded from prominence. ... Today's version of the story reverses the signs. Productivity has accelerated but workers have become accustomed to the slow wage growth since the 1970s." Figure 1 clearly shows that wages have been trailing productivity over the past thirty years and, on average, the labour share has been on a downward slope.

The downward trend of the labour share after the 1970s shifted the focus away from the wage-productivity growth mismatch as a determinant of unemployment, towards that of the role of labour market institutions. This was epitomised by the influential 1994 OECD Jobs Study which argued that, while wage-push factors (such as unemployment benefits, firing restrictions, minimum wages, union power, and the tax wedge) are responsible for the rise in unemployment, active labor market policies can reduce it. Note that this point of view is in the line of the Layard, Nickell and Jackman (1991), LNJ, contribution to the literature. LNJ develop a model in a Cobb-Douglas framework which, as we show in Section 3, implies a constant labour share that is neutral to employment.

This paper challenges the established view of treating the labour income share as innocuous to employment and, instead, investigates its impact on the evolution of employment. To substantiate the analytical exposition of Section 3, we provide empirical models of wage setting and employment equations for France, Germany, Italy, Japan, Spain, the UK, and the US (i.e. the G7 countries, where Spain has substituted Canada) ${ }^{3}$ using annual data over the 1960-2008 period. Our findings show that the time-varying labour share of these countries has significantly affected their employment trajectories across decades. This indicates that the evolution of the wage-productivity gap should play an instrumental role in policy making.

While a constant labour share restraints economic reasoning simply into a demandand supply-side settlement, a time-varying wage gap ignites the distributional aspect of macro-labour policies as well.

\footnotetext{
${ }^{2}$ Grubb, Jackman and Layard (1982), and Bruno and Sachs (1985) are among the influential papers.

${ }^{3}$ Or the European G5 group plus US and Japan (Blanchard, 2006, p. 15).
} 
Figure 1. Labour income shares

b. Germany
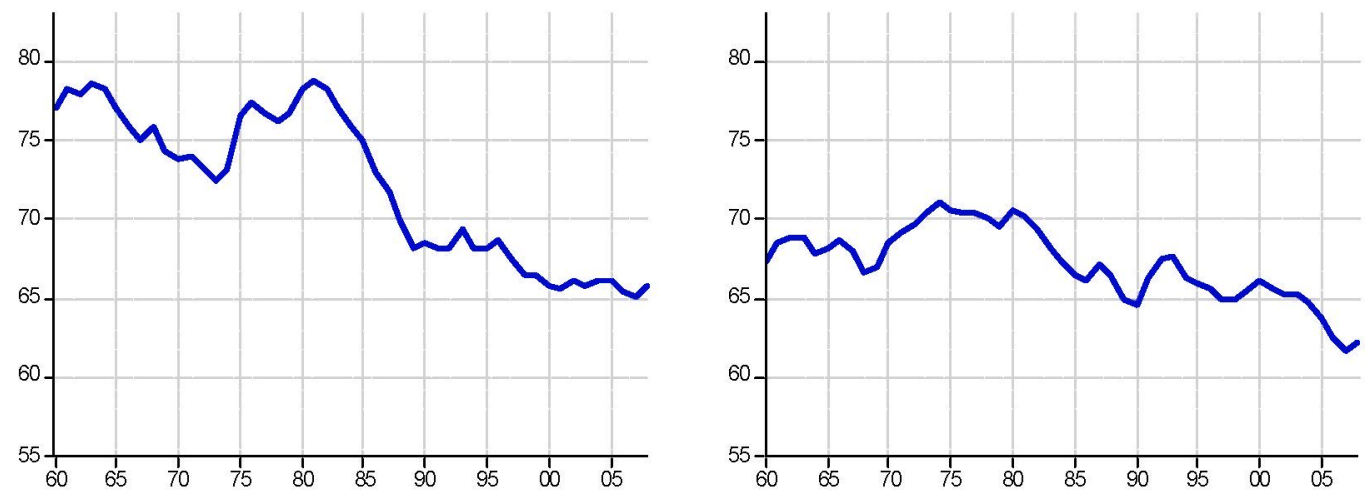

c. Italy

d. Japan
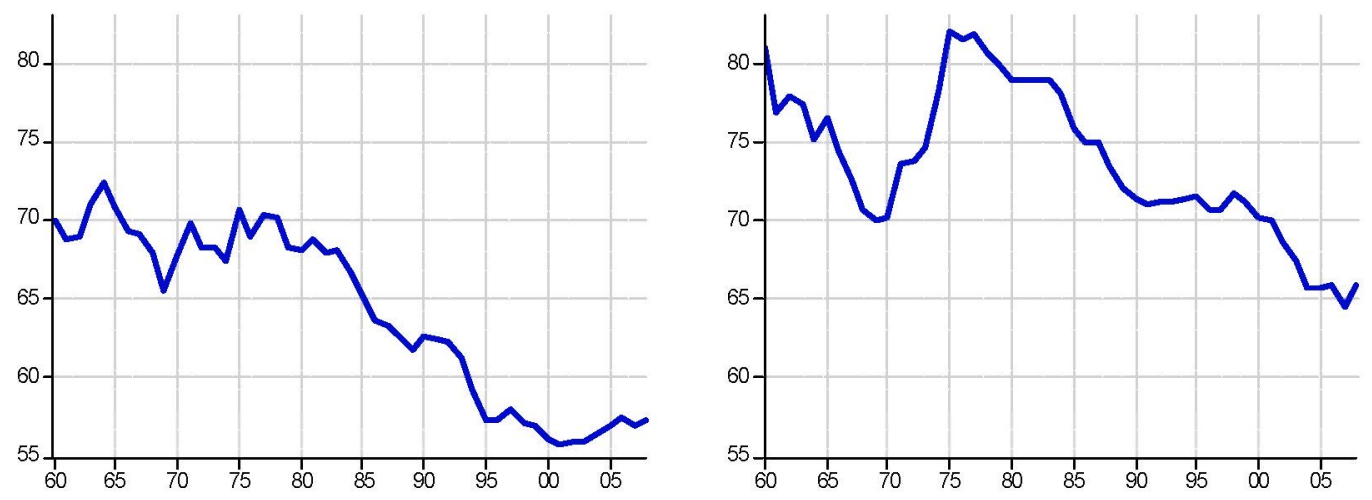

e. Spain

f. UK
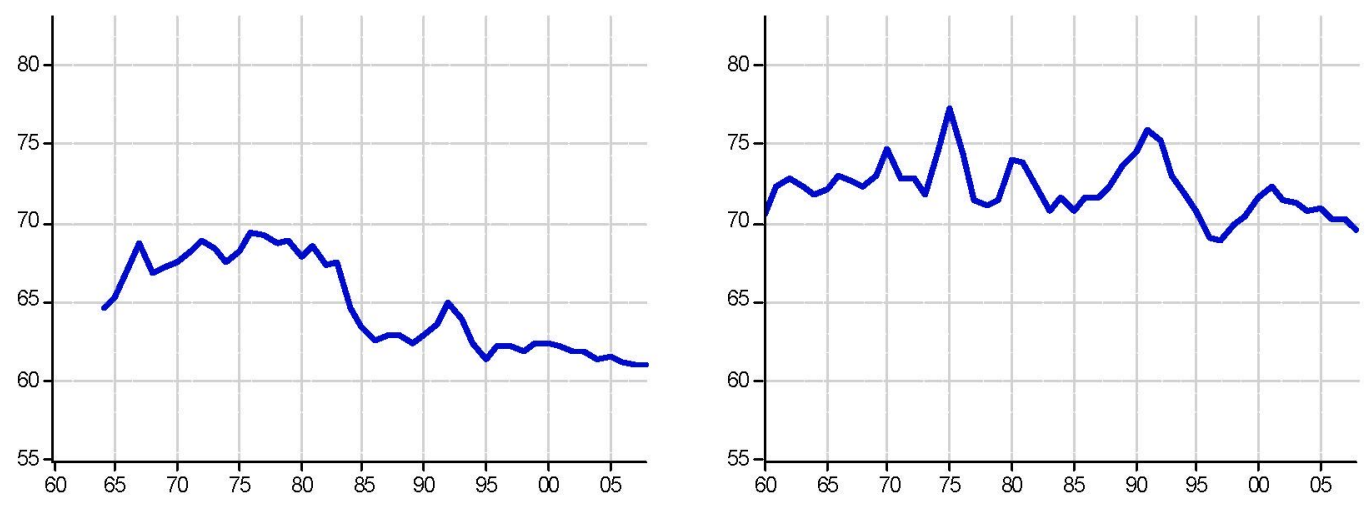

g. Us

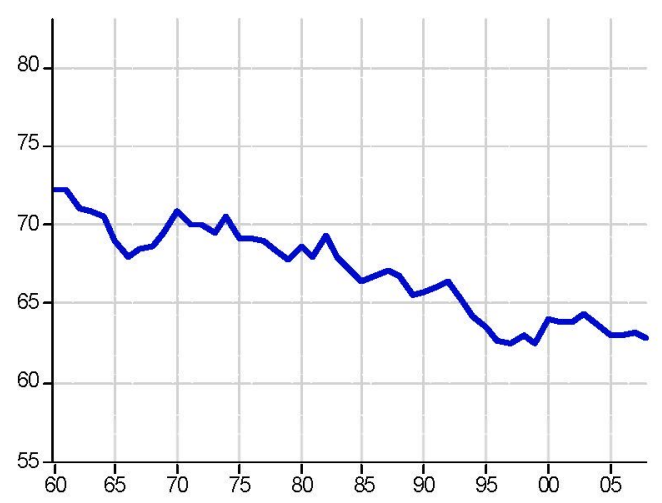


Put differently, a constant labour share focuses on the battle of the markups and leaves the conquest of the pie in obscurity. Although an investigation of the reason(s) that keep workers 'accustomed"4 to lower labour shares is beyond the scope of this study, we endeavor to address the issue of the labour share effects on the income distribution in future work.

The rest of the paper is structured as follows. Section 2 outlines the evolution of the labour share and briefly comments on income inequality. Section 3 analyses frictional growth and illustrates the impact of the wage gap on employment through a stylised model of wage setting and labour demand equations. Section 4 gives data sources, variable definitions, and outlines the econometric methodology. Section 5 discusses the empirical results, and Section 6 presents the dynamic contributions of the labour share to employment. Section 7 concludes and gives suggestions for future work.

\section{A Bird's Eye View of the Labour Share}

To set the stage of our study, we give a summary description of the time series characteristics of the labour income shares and briefly discuss some associated developments in the economic background. Although widely assumed in the literature, the theoretical property of a constant labour share is strongly refuted by reality. The plots in Figure 1 show that, on average, the labour share has evolved along a downward path over the past five decades in all of the seven countries we examined (as explained in Section 4, the labour share is adjusted for self-employment income).

Table 1 presents this picture in a nutshell by recording the highest value attained by each country, the end of sample value, and the difference between the two. The disparity between the top value of the labour share and its end of sample (2008) values observed in each country is in the range of 7.7 and 16.2 percentage points. Japan in 1975 had the highest labour share of $82.10 \%$, while Italy in 2001 witnessed the lowest value of $55.84 \%$. These two countries (and to a lesser degree France) exhibit a relatively wide range of labour share values, almost double the size of the other four countries.

Table 1. Summary information for labour income shares

\begin{tabular}{cccccccc}
\hline & France & Germany & Italy & Japan & Spain & UK & US \\
\cline { 2 - 7 } Top value (\%) & 78.76 & 71.12 & 72.41 & 82.10 & 69.48 & 77.29 & 72.23 \\
(year) & $(1981)$ & $(1974)$ & $(1964)$ & $(1975)$ & $(1976)$ & $(1975)$ & $(1961)$ \\
2008 value (\%) & 65.71 & 62.26 & 57.36 & 65.91 & 60.98 & 69.61 & 62.85 \\
Top-2008 (pp) & 13.05 & 8.86 & 15.05 & 16.19 & 8.5 & 7.68 & 9.38 \\
\hline
\end{tabular}

As shown in Table 1 and Figure 1, the evolution of the UK labour share is quite distinctive: it features the least wide range of labour share values, and it is quite volatile.

\footnotetext{
${ }^{4}$ To use the phrase of Ball and Mankiw (2002, p. 130).
} 
On the other hand, surprisingly so, the overall picture of Germany resembles that of the US as the labour shares in both countries are characterised by rather smooth time paths and a similar range of values. Nevertheless, in Section 6 we show that there are significant differences between the labour share changes of the two countries in each decade and their concomitant employment contributions. Also, note that some countries experienced an accelerated reduction in the their labour share during some periods, in the sense that the labour share was falling by more than one percentage point (pp) per year. For example, the labour share drop in France was 10.53 pp from 1981 to 1989 (slope=-1.32); in Spain the drop was $6 \mathrm{pp}$ from 1981 to 1986 (slope=-1.2); in the UK the labour share fell by 6.97 pp during 1991-97 (slope=-1.16); and in Italy it fell by 5.41 pp over the first half of the nineties (slope=-1.08). Furthermore, the Spanish labour share apparently displays a downward shift in its regime from the eighties onwards. We revisit the evolution of these labour shares in Section 6, where we focus on the wage gap changes in each decade and examine their employment contributions.

Recent literature has identified three interrelated factors as responsible for the decline in the labour shares: globalisation, technological progress, and product and labour market policies. The mechanisms through which compensation and job creation grow at a rate slower than economic growth are, among others, trade shares and terms-of-trade prices, foreign direct investment, offshoring, migration flows, and financial openness (IMF, 2007). In addition, technological progress tends to increase returns to capital and, thus, the capital income share. In turn, in seeking to maintain competitiveness, the product and labour market policies typically undertaken have tended to weaken the bargaining position of labour vis-à-vis the firm (Bentolila and Saint-Paul, 2003; Bental and Demouguin, 2010).

Given that the labour share represents the part of the economic pie that goes to labour, rather than profits, distributional issues at the core of this concept remain intact whether we call it labour income share (wage share) or wage-productivity gap (real unit labour cost). It is important to highlight that the downward sloping trajectory of the labour share has been accompanied by a worsening income inequality. The latter has been documented by a variety of authors in both the academia and the press.

In their investigation of wealth and income inequality in the US in 1982-2000, Wolff and Zacharias (2006) evidence a gain of 9.5 percentage points in the income share of the top decile (from $33.4 \%$ to $42.9 \%$ ). This increase in the share of the top decile is in stark contrast to the losses in the share of the aggregate economic pie experienced by the percentiles in the bottom 90 percent of the income distribution. The inequality gap is further magnified when we look at the very high end of the distributional spectrum: the share of the top percentile increased from $9.9 \%$ to a staggering $17.4 \%$. These results are in line with Piketty and Saez (2006) who find that during the 20th century the top

\footnotetext{
${ }^{5}$ A slope $<-1$ means that the reduction rate exceeded 1 pp per year over a given period.
} 
percentile has fluctuated from around $18 \%$ before WWI, to only around $8 \%$ in the $1960 \mathrm{~s}$ and $1970 \mathrm{~s}$, and back to around $17 \%$ by 2000 .

In Japan, traditionally considered as an egalitarian society, inequality has been rising since the eighties. Moriguchi $(2010$, p. 7$)$ links this increase "with a faster growth of wage income at the high end of the distribution". He also states (p. 23) that the recent increases in the top $1 \%$ wage group are modest when compared to those in the US. Regarding the rich-poor divide in the UK, it is wider now than 40 years ago according to the report of the National Equality Panel: An Anatomy of Economic Inequality in the UK, January $2010 .^{6}$

Furthermore, Bourguignon and Morrisson (2002) examine inequality among world citizens using data from 1820 to 1992 and find that, while the income share of the top decile was relatively stable about 50 percent throughout the 1950 s to the 1970 s, it started increasing in 1980, reaching its highest value of 53.4 percent in 1992 (ibid, Table 1, p. 731-732.) Edward (2006), using density and growth curves, presents a holistic analysis of global poverty, growth, and inequality. Among his findings is that the "poorest half of the world's population received less that one-tenth of the global growth in the 1990s." (p. 1677); furthermore, for the middle-income earners outside China (roughly one billion people between the 50th and 70th percentiles), consumption hardly changed from 1993 to 2001.

Among others, in the Financial Times we read that "Between 2000 and 2006 the US economy expanded by 18 per cent, whereas real income for the median working class dropped by 1.1 per cent ... Meanwhile, the top tenth saw an improvement of 32 per cent in their incomes, the top 1 per cent a rise of 203 per cent the top 0.1 per cent a staggering gain of 425 per cent." 7 The Economist reports that, since 2000, "The fruits of productivity gains have been skewed towards the highest earners, and towards companies, whose profits have reached record levels as a share of GDP." ${ }^{8}$ Wolff and Zacharias (2006, p. 5) note that in 2004, the median net worth of the individuals in the Forbes 400 list was $\$ 1.5$ billion "as compared to the median net worth of $\$ 93,000$ for all other households." According to Llense $(2010$, p. 1) "the sharp increase in globalization and the last privatization wave have promoted the shaping of a market for executives in France."

As the increase in the share of the top percentile has been accompanied by the exceptional growth in top executives' pay relative to the salaries of employees, the issue of whether the so called "working rich" ${ }^{9}$ have replaced top capital owners (the "rentiers")

\footnotetext{
${ }^{6}$ See also the Joseph Rowntree Foundation "New poverty and wealth maps of Britain reveal inequality to be at 40-year high", 17 July 2007, www.jrf.org.uk.

${ }^{7}$ Financial Times, 29/10/2008, Stuck in the Middle by Edward Luce.

${ }^{8}$ The Economist, 2006, June 17, Special report: Inequality in America.

9 "Forbes popularised this term. However, the magazine used it in the sense that the wealthiest Americans hold jobs rather than in the sense that the wealthiest depend mainly on labour income as their chief source of income." (Wolff and Zacharias, 2006, p. 12).
} 
at the top of the economic ladder is open to debate. ${ }^{10}$ Economists of the Washington consensus have labelled such a wealth redistribution 'median wage stagnation' and are stunned about the complexity of the problem and its causes. Others dub it the 'silent recession'. ${ }^{11}$

We view globalisation as a phenomenon that encapsulates (among other things) the interplay of technological progress and product/labour market policies in a world of growing inequality. From the above statistics and selected literature, it is apparent that globalisation leads to higher employment, whilst it is accompanied by a more unequal income distribution. Given that the boost in employment is one side of the globalisation coin, and its flip side is the worsening of inequality, the labour share is the footprint of the globalised employment/income inequality mix (see Figure 2).

Figure 2. Anatomy of the labour share channel

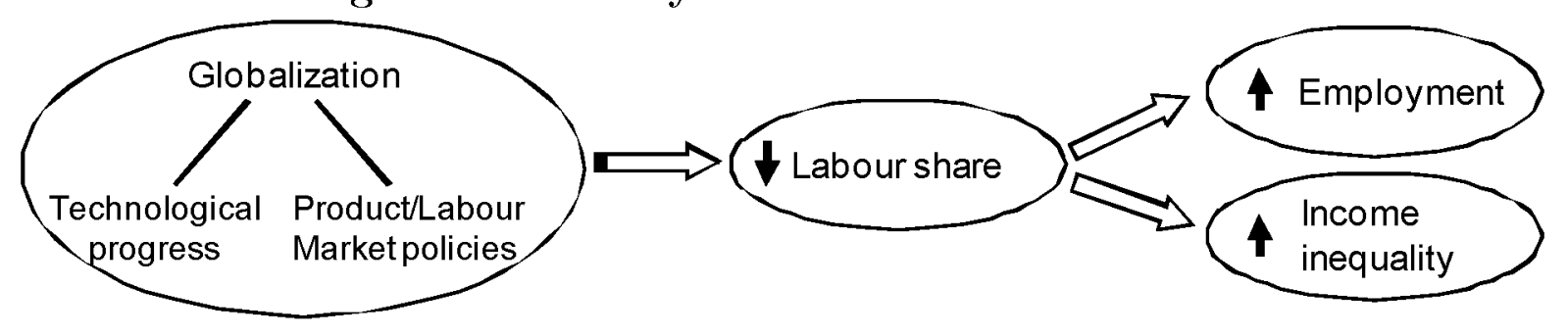

\section{The Impact of the Labour Share on Employment}

Conventional labour market analysis asserts that the labour share is constant and neutral to employment. The property of constancy stems from the assumption of a Cobb-Douglas (CD) production function, whereas employment neutrality arises from the perception that the steady state of the wage curve coincides with its long-run solution. We argue that the steady-state and long-run versions of wage setting are identical in the absence of dynamics and growth. We call the interplay between dynamics and growth frictional growth and show that it is responsible for the disparity between the steady-state and long-run solutions of dynamic equations.

In what follows, we iterate on our viewpoint through the analysis of static/dynamic versions of stylised wage and employment equations. The use of such stylised models is encouraged by Blanchard (2009, p. 225-226) who ends his review on the 'state of macro' with three "hopes/pleas", among which are "the rehabilitation of partial equilibrium modeling" and "the relegalization of shortcuts and simple models... Approximating complex relations by simple ones helps intuition and communication."

\footnotetext{
${ }^{10}$ For example, Wolff and Zacharias (2006) do not support this issue, whereas Piketty and Saez (2006) argue in its favour.

${ }^{11}$ Financial Times, 29/10/2008, Stuck in the Middle by Edward Luce.
} 


\subsection{Wage Setting vis-à-vis Productivity}

\subsubsection{A Static Wage Curve}

One of the simplest ways to formulate the wage curve is to assume a Nash bargaining process, where employees receive an average compensation in exchange of their work and firms obtain the average product less the average compensation (in case of an individual negotiation the reference would be the marginal product):

$$
\Omega=(W)^{\gamma}\left(\frac{Y}{N}-W\right)^{1-\gamma}
$$

where $\gamma$ and $(1-\gamma)$ are, respectively, the workers' and the firms' bargaining power, $W$ is the real wage, $Y$ denotes real output and $N$ is employment. Maximisation of equation (2) involves the first-order condition

$$
\frac{\partial \Omega}{\partial W}=\gamma(W)^{\gamma-1}\left(\frac{Y}{N}-W\right)^{1-\gamma}-(1-\gamma)(W)^{\gamma}\left(\frac{Y}{N}-W\right)^{-\gamma}=0
$$

which gives

$$
W=\gamma\left(\frac{Y}{N}\right) \quad \text { or } \quad \gamma=\frac{W N}{Y}=\text { labour share. }
$$

Note that equation (3) implies a constant labour share and a one-to-one relationship between wages and productivity (in logs). This is the familiar neoclassical world picture, where higher productivity is reflected fully in higher real wages.

\subsubsection{Wage Dynamics and Frictional Growth}

The introduction of wage dynamics distorts the above neoclassical dictum (at least) in the short run. Let us consider that wages do not adjust fully to productivity movements in the context of a stylised wage-setting equation:

$$
w_{t}=\alpha_{1} w_{t-1}+\left(1-\alpha_{1}\right) p r_{t}
$$

where $w_{t}$ denotes log real wage, $p r_{t}$ is labour productivity (in logs), and the autoregressive parameter is $0<\alpha_{1}<1$. Higher order lags, other explanatory variables (i.e. unemployment and wage-push factors, such as benefits and union power), and the error term are ignored for analytical convenience. The static form of wage setting can be thought of as arising from the naive Nash bargain described in the previous section, or from the maximisation of a more elaborate Nash bargain in the context of a CES production function (Manning, 1993, equation (21)).

The dynamics in the real wage equation (4) may arise from wage/price staggering 
(Taylor, 1979, 1980), or wage aspirations (i.e. wages that workers consider fair). For example, Ball and Moffitt (2002) consider the possibility that a productivity shift is not matched immediately by a shift in wage aspirations, because these partly depend on past wage increases. Alternatively, wage dynamics can be seen as the reconciliation of "the empirical Phillips-curve relation and the theoretical wage-curve relation" (Blanchard and Katz, 1999, p. 69). In particular, Blanchard and Katz consider the 'wage curve' of Blanchflower and Oswald (1994), which represents a negative relation between real wage and unemployment given the reservation wage and productivity, and incorporate into it the likely dependence of the reservation wage on lagged wage.

We should point out that the dynamic wage-setting (4) is in line with the dominant view that real wages are tied closely to labour productivity in the long run. For example, Galí (2010) derives a theoretical model where " $g$ is the rate of growth of productivity (and real wages) in the steady state" (p. 8); the model presented by Ball and Moffitt (2002) has the "feature that productivity, real wages, and real-wage aspirations all grow at the same rate in a steady state" (p. 3, nber w8421); and Ball and Mankiw (2002, p. 129) argue that "In a steady state with constant growth of labor productivity, the growth of real wages is determined by the growth of productivity, as suggested by neoclassical theory (and empirical evidence)."

Put differently, the salient characteristic of the real wage equation (4) is a unitary long-run elasticity of wages with respect to productivity. This becomes apparent when we rewrite it as

$$
w_{t}=\underbrace{p r_{t}}_{\text {'trend' or steady-state }}-\underbrace{\frac{\alpha_{1}}{1-\alpha_{1}} \Delta w_{t}}_{\substack{\text { 'cycle' if long-run grow th }=0 \\ \text { 'frictional growth' otherwise }}},
$$

where $\Delta$ is the first difference operator. Taking first differences, and assuming that the growth rate of productivity stabilises in the long run, we obtain the neoclassical benchmark:

$$
\Delta w^{L R}=\Delta p r^{L R}
$$

where the superscript ${ }^{L R}$ denotes the long-run value of the variable. Ball and Mankiw (2002, p. 129) state that "In a steady state with constant growth of labor productivity, the growth of real wages is determined by the growth of productivity, as suggested by neoclassical theory (and empirical evidence)." The above result is also "a standard equation for price inflation" in Ball and Moffitt (2002, equation (4)). In addition, the unit long-run elasticity of real wage with respect to productivity is a feature of the real wage model in Hatton (2007, equation (1), p. 480).

Finally, observe that the first term of the real wage equation (5) is the 'trend' of $w_{t}$, while the second term captures the frictional growth of the model. If productivity does 
not grow in the long run, the real wage will stabilise in the long run. In this case frictional growth is zero and the second term of equation (5) describes the 'cyclical' component of real wages. As can be seen from equations (5)-(6), the long-run state of wage setting is decomposed into the steady-state solution and frictional growth:

$$
\underset{\text { long-run state }}{w^{L R}}=\underset{\text { steady-state }}{p r^{L R}+} \underbrace{\left(\frac{-\alpha_{1}}{1-\alpha_{1}} \Delta p r^{L R}\right) .}_{\text {frictional growth }}
$$

It is important to note that the long-run elasticity of the real wage with respect to productivity is unity regardless of whether frictional growth is zero or not. We believe that the focus of economists on elasticities has led them to generally disregard the phenomenon of frictional growth, i.e. the interplay between lags and growth, in macro-labour models. However, it needs to be stressed that frictional growth arises under the plausibility of a dynamically growing environment (for example, one in which productivity grows).

\subsection{Labour Demand}

\subsubsection{Cobb-Douglas and Factor Shares}

Let us consider the following CD production function:

$$
Y=A N^{1-\beta} K^{\beta}, \quad \text { or } \quad \frac{Y}{N}=A\left(\frac{K}{N}\right)^{\beta},
$$

where $K$ is capital stock, $A$ is technology, and $\beta(0<\beta<1)$ accounts for the relative influence of capital and employment on output.

The maximisation problem is

$$
\max \Pi=A N^{1-\beta} K^{\beta}-W N-r K
$$

where $\Pi$ denotes profits, the price of labour is the real wage $(W)$ and the price of $K$ is the real rental price proxied by the real interest rate $(r)$.

The first-order condition (FOC) with respect to labour, $\frac{\partial \Pi}{\partial N}=0$, gives

$$
\begin{aligned}
(1-\beta) A K^{\beta} N^{-\beta}-W & =0 \Rightarrow \\
(1-\beta) A\left(\frac{K}{N}\right)^{\beta} & =W .
\end{aligned}
$$

Substituting equation (8) into (9), we obtain

$$
(1-\beta) \frac{Y}{N}=W \quad \text { or } \quad(1-\beta)=\frac{W N}{Y} \equiv \text { labour share. }
$$


In other words, profit maximisation under a CD production function scheme implies a constant labour income share. ${ }^{12}$

Similarly to the derivation of the labour share (10), algebraic manipulation of the FOC with respect to capital, $\frac{\partial \Pi}{\partial K}=0$, gives the following capital share (also a constant):

$$
\beta \frac{Y}{K}=r \quad \text { or } \quad \beta=\frac{r K}{Y} \equiv \text { capital share. }
$$

Note that in a competitive economy $\Pi=0 \Longrightarrow Y=W N+r K$, production is thus distributed according to the marginal products of its factors and, naturally, the constant labour and capital shares add up to one.

We should point out that Blanchard (2006) calls the profit maximising wage the 'warranted wage', the wage set in bargaining the 'bargained wage', and argues that "If, for given labour market conditions, the bargained wage grows faster than the warranted wage, equilibrium employment will decline..." (ibid, p. 13-14.) In the context of the above profit maximisation framework and the bargaining process (2), this means that employment stability is achieved when the 'warranted wage' (10) equals the 'bargained wage' (3):

$$
1-\beta=\gamma
$$

A bargained wage growing faster that the warranted one, $\gamma>1-\beta$, leads to lower employment and a higher natural rate of unemployment.

Next, the labour demand can be obtained by expressing the first-order condition (9) in terms of employment:

$$
(1-\alpha) A K^{\alpha} W^{-1}=N^{\alpha} \quad \Rightarrow \quad N=[(1-\alpha) A]^{1 / \alpha} K W^{-1 / \alpha}
$$

Thus, in logarithms:

$$
\begin{aligned}
\ln N & =\frac{1}{\alpha} \ln (1-\alpha)+\frac{1}{\alpha} \ln A+\ln K-\frac{1}{\alpha} \ln W, \quad \text { i.e. } \\
\text { labour demand } & =f \text { (technological change, capital, real wage }) .
\end{aligned}
$$

In their essay on the Cambridge controversies, Cohen and Harcourt (2003, p. 199) set the stage of the historical debates on capital theory with Joan Robinson's complaint: “... the production function has been a powerful instrument of miseducation. The student of economic theory is ... instructed to assume all workers alike, and ... is told something about the index-number problem in choosing a unit of output; then he is hurried on to the next question, in the hope that he will forget to ask in what units $K$ is measured.

\footnotetext{
${ }^{12}$ Clearly, the labour share will not remain constant without assuming a CD production function. For example, Manning (1993, p. 104), in the context of maximising a Nash bargain, uses a CES technology and derives a time-varying share of labour in output.
} 
Before he ever does ask, he has become a professor, and so sloppy habits of thought are handed on from one generation to the next."

As far as our understanding of labour markets is concerned, we hold the view that although the workings of the CD production function offer useful analytical insight, its limitations are profound and should not be discounted.

\subsubsection{Employment vis-à-vis the Wage Gap}

Let us consider the following standard log-linear labour demand equation:

$$
n_{t}=\phi_{0}+\phi_{1} n_{t-1}-\phi_{2} w_{t}+\phi_{3} p r_{t}+\text { "other variables" }+\varepsilon_{t},
$$

where $n_{t}$ denotes employment and the $\phi$ 's are positive parameters; the autoregressive parameter is $0<\phi_{1}<1$ captures employment adjustment costs, such as costs of hiring and firing, search costs, and training costs. The explanatory set may include variables like the real interest rates or real balances, and financial wealth (see Section 5). We should point out that, in the light of the labour demand equation (14) obtained by the CD framework, productivity $(p r)$ can be thought of as capturing technological change. (This is common in the literature - see, for example, Blanchard, 2006.)

Similarly to wage setting above, higher order lags, "other variables" and the strict white noise error term, $\varepsilon_{t}$, are ignored without loss of generality. Also, for expositional simplicity, we assume that $\phi_{3}=\phi_{2}$ and (ignoring other variables and the error term) we write:

$$
n_{t}=\phi_{0}+\phi_{1} n_{t-1}-\phi_{2}\left(w_{t}-p r_{t}\right)
$$

Note that the $\log$ difference between the real wage and productivity is a key element in the unemployment rate equation (2) used by (Hatton, 2007), which can also be thought of as a dynamic labour demand equation (p. 480). We can further justify the stylised employment equation (15) or (16) in the words of Blanchard (2009, p. 222) "Small models are essential communication and exposition devices. When successful, they reduce a complex issue to its essence. They can either embody the wisdom of larger, more explicit microfounded models..."

First differencing of equation (16), and the use of equation (6), shows that the longrun/steady-state employment growth is zero:

$$
\Delta n^{L R}=-\frac{\phi_{2}}{\left(1-\phi_{1}\right)}\left(\Delta w^{L R}-\Delta p r^{L R}\right)=0 .
$$


Furthermore, the employment equation (16) can be reparameterised as

$$
n_{t}=\frac{\phi_{0}}{1-\phi_{1}}-\frac{\phi_{2}}{\left(1-\phi_{1}\right)}\left(w_{t}-p r_{t}\right)-\frac{\phi_{1}}{1-\phi_{1}} \Delta n_{t}
$$

Observe that, since the last term of equation (18) vanishes in the long run (due to equation (17)), we obtain the following long-run labour demand function:

$$
\begin{aligned}
n^{L R} & =\frac{\phi_{0}}{1-\phi_{1}}-\frac{\phi_{2}}{\left(1-\phi_{1}\right)}\left(w^{L R}-p r^{L R}\right) \\
& =\frac{\phi_{0}}{1-\phi_{1}}+\frac{\phi_{2} \alpha_{1}}{\left(1-\alpha_{1}\right)\left(1-\phi_{1}\right)} \Delta p r^{L R} .
\end{aligned}
$$

In the light of the analysis of wage dynamics and frictional growth in equation (5), the above implies that the wage-productivity gap plays an influential role in employment dynamics at all time horizons. In particular, the long-run state (19) of labour demand shows that the wage gap has a long-run effect on employment due to frictional growth in wage setting. The labour share cannot affect long-run employment under the rather implausible assumptions that productivity ceases to grow in the long run and the real wage is independent of past wage-setting decisions.

\subsection{Implication of Frictional Growth}

To enhance our understanding of the phenomenon of frictional growth, we illustrate (without loss of generality) its workings within a "user-friendly" labour market framework. As in the previous sections, we follow the dominant view in the literature, i.e. we assume a unitary long-run elasticity of wages with respect to productivity. For expositional ease, and in line with conventional wisdom, we first present the steady-state equations of wage setting $(W S)$ and labour demand $(L D):^{13}$

$$
\begin{aligned}
& \text { steady-state } W S: \quad w=p r+n+(\text { impact of exogenous } x) \text {, } \\
& \text { steady-state } L D \quad: \quad n=-w+p r+(\text { impact of exogenous } z) \text {. }
\end{aligned}
$$

To keep algebraic and geometric simplicity we further assume that the elasticity of wage setting with respect to employment and the wage elasticity of labour demand are equal to unity in absolute value. Note that, while the inclusion of employment as an explanatory variable of real wages (20) describes an environment of imperfect competition (and/or information), the wage setting equation (4) prevails under perfect competition. The efficiency-wage and insider-outsider literature have shown that there is a positive relation

\footnotetext{
${ }^{13}$ Note that while the exogenous set of variables $x$ and $z$ are important for the identification of the $W S$ and $L D$ schedules, they play no role in the analysis below and are thus ignored.
} 
between wages and employment. The analysis of the above prototype real wage and employment equations is also portrayed in Figure 3 below. The $45^{\circ}$ downward-sloping $W S$ and upward-sloping $L D$ schedules intersect at point $E$, which determines the initial equilibrium values of employment and real wage, $n$ and $w$, respectively.

Now suppose that productivity increases by one unit to a new level, $p r^{\prime}$. This causes the wage curve to shift to the left at the $W S^{\prime}$ schedule, and labour demand to shift to the right at the $L D^{\prime}$ schedule. Both shifts, which are parallel and of the same size, $\frac{\partial w}{\partial p r}=\frac{\partial n}{\partial p r}=1$, are pictured in Figure 3 by the distance $E E^{\prime}$. The intersection point $E^{\prime}$ between wage setting $\left(W S^{\prime}\right)$ and labour demand $\left(L D^{\prime}\right)$ determines the new equilibrium values of employment and real wage, $n^{\prime}$ and $w^{\prime}$. It is clear that, while the rise in productivity leads to a wage rise of the same magnitude in the steady state, $w^{\prime}-w=p r^{\prime}-p r=E^{\prime} E=1$, it produces no change in employment, $n^{\prime}=n$. This is because in equations (20)-(21) productivity gains are fully translated into wage rises that offset employment creation.

This is not the case in an economy characterised by dynamics and long-run growth. To show this we modify the labour market equations (20)-(21) by introducing an autoregressive element in each of them, while keeping the same steady-state solutions:

$$
\begin{aligned}
W S: & w_{t}=\alpha w_{t-1}+(1-\alpha) p r_{t}+(1-\alpha) n_{t} \\
L D & : \quad n_{t}=\phi n_{t-1}-(1-\phi) w_{t}+(1-\phi) p r_{t}
\end{aligned}
$$

where $0<\alpha, \phi<1$ denote the autoregressive parameters. Let us rewrite equations $(22)-(23)$ as

$$
\begin{aligned}
W S: & w_{t}=p r_{t}+n_{t}-\frac{\alpha}{1-\alpha} \Delta w_{t}, \\
L D & : \quad n_{t}=-w_{t}+p r_{t}-\frac{\phi}{1-\phi} \Delta n_{t},
\end{aligned}
$$

where $\Delta(\cdot)$ denotes the growth rate of the variable.

For expositional ease, let growth in the above model stem solely from productivity, and assume that the growth rate of productivity stabilises in the long run, $\Delta p r^{L R}$. It follows that the long-run state of wage setting is

$$
\begin{aligned}
\text { long-run state } W S: w & =p r+n-\frac{\alpha}{1-\alpha} \Delta w^{L R} \\
& =p r+n-\frac{\alpha}{1-\alpha} \Delta p r^{L R}
\end{aligned}
$$

since it can be shown that $\Delta w^{L R}=\Delta p r^{L R}$ (equation (6)) is also valid in the above dynamic model. ${ }^{14}$ The long-run state of wage setting (26) is plotted by the $W S^{L R}$ schedule

\footnotetext{
${ }^{14}$ In the context of dynamic wage setting, the benchmark result suggested by neoclassical theory (and empirical evidence), namely that the growth of real wages is determined by the growth of productivity,
} 
in Figure 3.

Figure 3. Employment and productivity

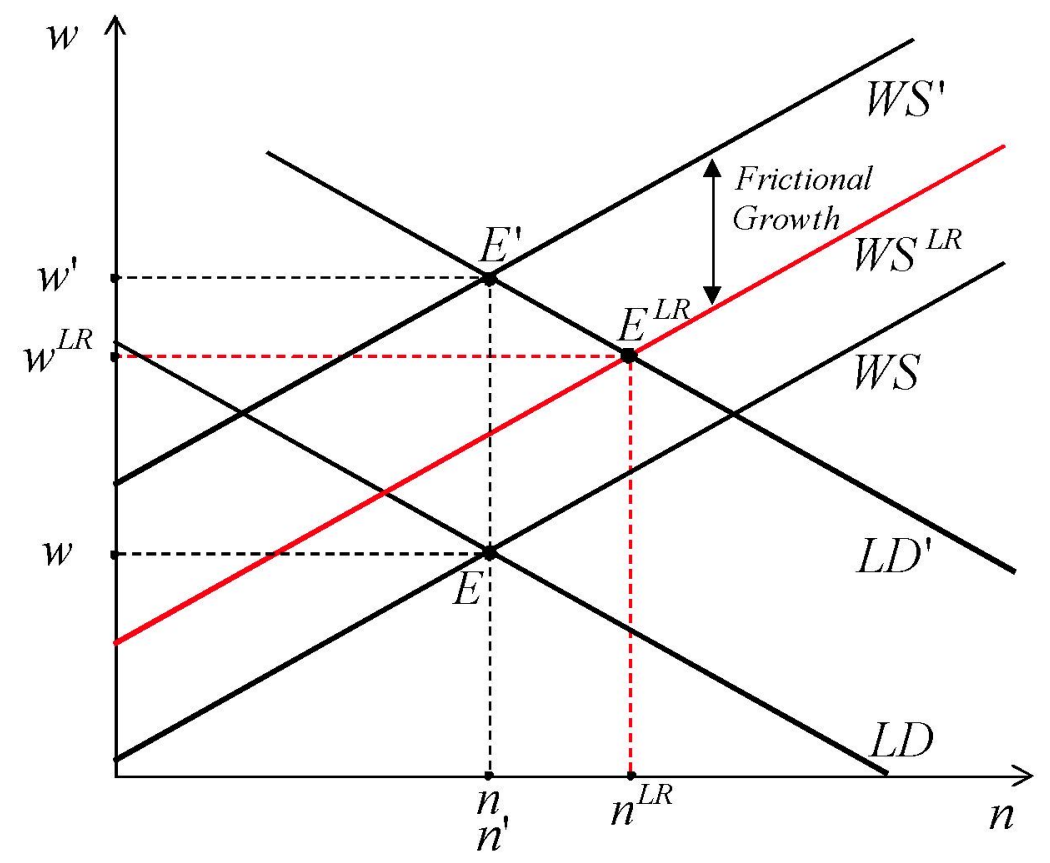

Observe that in the absence of long-run growth and/or dynamics, the long-run state (26) reduces to the steady state (20). Thus the elegant relationship:

$$
\text { long-run state } W S=\text { steady-state } W S+\text { Frictional Growth. }
$$

Frictional growth, a long-run phenomenon, encapsulates the interplay of dynamics and growth and represents the distance between the $W S^{\prime}$ and $W S^{L R}$ schedules in Figure 3. The intersection point $E^{L R}$ between $W S^{L R}$ and $L D^{\prime}$ gives the long-run equilibrium values of the dynamic labour market model (22)-(23). ${ }^{15}$ In the presence of dynamics and growth, the rise in productivity to a new level $p r^{\prime}$ leads to employment creation $\left(n^{L R}>n^{\prime}\right)$, since frictional growth implies that productivity gains are not fully translated into wage rises.

is obtained by the first difference of equation (24)

$$
\Delta w_{t}=\Delta p r_{t}+\Delta n_{t}-\frac{\alpha}{1-\alpha} \Delta^{2} w_{t}
$$

and (i) the plausible assumption that wage growth stabilises in the long run, i.e. $\Delta^{2} w^{L R}=0$, and (ii) the simplifying assumption that the only source of long-run growth in the model is productivity (i.e. $\Delta n^{L R}=0$ ). In the long run, under these conditions, the above equation reduces to

$$
\Delta w^{L R}=\Delta p r^{L R} \text {. }
$$

\footnotetext{
${ }^{15}$ Note that under the assumption that productivity is the only source of growth, the long-run state of labour demand is equivalent to its steady-state, i.e. the $L D^{\prime}$ and $L D^{L R}$ schedules coincide.
} 


\section{Empirical Approach}

We should emphasise that our modelling approach does not fall into the murky waters of the theoretical versus data-driven debate, since the real wage and employment equations (4)-(15) rely on the bidirectional feedback between a prior viewpoint and the observations-driven analysis. Consequently, the aim of our macroeconometric methodology is to investigate the symbiotic relationship between theory and evidence, rather than compartmentalising them and then bridging the gap between theory and data. Regarding the latter, Blanchard (2009, p. 224) argues that "Reconciling the theory with the data has led to a lot of unconvincing reverse engineering."

\subsection{Data and Variable Definitions}

We use annual data from the OECD (Economic Outlook, Annual Labour Force Statistics), the IMF, and Bloomberg running from 1960 to 2008 for France, Germany, Italy, Japan, Spain, the UK and US. The variables entering the wage and employment equations are shown in Table 2 and are as follows. Employment $(n)$ is the total number of employees in logs, the unemployment rate is given by $u=l-n$, where the force $(l)$ is the $\log$ of total active population. The set of institutional variables includes social security benefits (b) as a percentage of GDP; trade union density $(u d)$, i.e. the number of wage and salary earners that are trade union members over the total number of wage and salary earners; the minimum wage $(w m)$ relative to the average wage of full-time workers; and direct and indirect taxes $\left(\tau^{d}, \tau^{i}\right)$ as a percentage of GDP. Depending on the availability of a money supply series, we proxy the rental price of capital by (i) real interest rates $(r)$, defined as the difference between the nominal interest rate and the inflation rate (defined as the rate of change of the GDP deflator), or (ii) real money balances $(r b)$, defined as a broad measure of money supply over the GDP deflator. Financial wealth $(f w)$ captures expectations on future productivity (Phelps and Zoega, 2001), and is defined as the log of the stock exchange index over the GDP deflator. ${ }^{16}$ We control for external factors through real oil prices ( $\mathrm{il}$ ), the degree of economic openness (open) defined as exports plus imports over GDP, and a standard measure of competitiveness (comp): the ratio of import prices over the GDP deflator (in logs). Finally, we also use private household consumption $(c)$ as percentage of GDP, and the log of working-age population ( $z$ ).

Real average wage, labour productivity, and labour income share deserve special attention. Empirically, the simple theoretical definition (1) of the labour share is affected by two measurement issues. First, total labour compensation should include both dependent and self-employment compensation. However, information on total compensation

\footnotetext{
${ }^{16}$ We experimented with this variable in Germany, Spain, the UK, and the US, using the DAX, IGBM (Índice General de la Bolsa de Madrid), FTSE, and S\&P 500 indices, respectively.
} 
supplied by the National Accounts excludes income generated by self-employees and, as a consequence, the appropriate measure of the labour income share requires some adjustments. Here we follow Gollin (2002) to adjust the labour share for self-employment income. Second, the standard measure of ouput is GDP at market prices which, in contrast to GDP at factor costs, includes taxes on production and imports, and does not include subsidies. Since these taxes and subsidies are not regarded as a component of generated income, they need to be excluded from the calculation of the labour income share.

Table 2. Definitions of variables

\begin{tabular}{ll|ll}
\hline$l s$ & labour share $(=w-p r)$ & $u$ & unemployment rate (\%) \\
$w$ & average total real compensation & $n$ & employment \\
$p r$ & labour productivity & $w m$ & minimum wage (\%) \\
$f w$ & financial wealth & $u d$ & trade union density (\%) \\
$r b$ & real balances & $\tau^{i}$ & indirect taxes (\% of GDP) \\
$r$ & real interest rates (\%) & $\tau^{d}$ & direct taxes (\% of GDP) \\
open & openness (\%) & $b$ & social security benefits (\% of GDP) \\
$c o m p$ & competitiveness & $z$ & working-age population \\
oil & real oil prices & $c n t$ & constant \\
$c$ & private consumption (\% of GDP) & $t$ & linear time trend \\
\hline \hline
\end{tabular}

Note: Variables are in logs unless otherwise indicated.

Sources: Bloomberg $(f w)$, IMF (oil), and OECD (rest of the variables).

Given these caveats, we have followed the Ameco methodology ${ }^{17}$ and computed the adjusted labour share as

$L S=\frac{\text { total compensation/dependent employment }}{\text { GDP at factor costs/total employment }}=\frac{\text { total compensation }}{\text { GDP at factor costs }} \frac{\text { total employment }}{\text { dependent employment }}$

Once the labour share is computed, we use equation (1) to retrieve the average wage per employee (including self-employment) as $W=\frac{L S * Y}{N}$, where $N$ is total employment and $Y$ is the standard measure of GDP at market prices. Note that $w, n, y$, and $l s$ are the $\log$ counterparts of $W, N, Y$ and $L S$, and, therefore, the wage-productivity gap, $w-p r$, is effectively the labour share.

\subsection{Econometric Methodology}

We apply the autoregressive distributed lag (ARDL) approach to estimate wage setting and labour demand equations for each of the seven countries in our sample. The ARDL procedure (also known as bounds testing approach) was developed by Pesaran (1997), Pesaran and Shin (1999), and Pesaran, Shin and Smith (2001) as an alternative to the popular cointegration/error-correction methodology. The advantage of the ARDL is that

\footnotetext{
${ }^{17}$ http://ec.europa.eu/economy_finance/ameco.
} 
it is not affected by the pre-testing problem implicit in the standard cointegration techniques (i.e. the Johansen maximum likelihood or the Phillips-Hansen semi-parametric fully-modified OLS procedures).

The voluminous literature on all the different types of unit root tests proposed since the influential paper by Dickey and Fuller in Econometrica 1981, is a clear manifestation of the problems involved in correctly identifying the order of integration of a time series. It can be shown that the ARDL yields consistent short- and long-run estimates irrespective of whether the regressors are $\mathrm{I}(1)$ or $\mathrm{I}(0)$, and thus it represents a rigorous econometric methodology.

We determine the dynamic specification of the real wage and employment equations by using the optimal lag-length algorithm of the Schwartz information criterion. It is important to note that the equations we select are dynamically stable and pass the standard diagnostic tests at conventional significance levels, i.e. they satisfy the conditions of linearity, structural stability, no serial correlation, homoskedasticity, and normality. In addition, we estimate the equations using 2SLS to take into account the issue of endogeneity. The results are shown in Tables 3 and 4 below. Note that all equations are well specified, the estimated sensitivities have plausible signs and magnitudes, and the fitted values track the actual data very well (see Figure A.1 in the Appendix).

\subsection{Wage Setting Estimations}

The estimations presented in Table 3 are empirical versions of equation (4) that was analysed in Section 3.

Note that the real wage estimations in Table 3 can be associated with the theoretical wage-unemployment equation (5), or (6), in Blanchard and Katz (1999), BK hereafter: the estimate of the autoregressive parameter, i.e. the coefficient of $w_{t-1}$, can be regarded as an estimate of the parameter $\mu \lambda$ in BK, while the estimate of the coefficient of $p r_{t}$, the productivity elasticity, corresponds to the BK parameter $(1-\mu \lambda)$. Contrary to the suggestion by BK (p. 71) that " $\mu \lambda=1$ may be a reasonable approximation for the United States", whereas "in European countries either $\mu$ or $\lambda$ or both are significantly less than 1", our estimates of the autoregressive parameter, and thus for the wage elasticity of productivity, are: $0.74, \underset{\text { US }}{0.70 a n} \underset{\text { France }}{0.70} \underset{\text { Italy }}{0.57} \underset{\text { UK }}{0.56, \underset{G}{0.40} 0.40 \text {, }}$ and $\underset{\text { Spain }}{0.15}$. Nevertheless, the classical assumption of a one-to-one relationship between real wages and productivity in the long run is valid in all the countries examined.

Also note that our empirical real wage equation is in line with the model used by Hatton (2007, equation (1)), where real wage depends on its lagged value, labour productivity, the unemployment rate and a vector of wage-push variables, and satisfies the restriction of a unitary long-run elasticity with respect to productivity. As Hatton (2007, p. 480) argues, this "may be thought of as encompassing the components of the feasible 
wage, represented by labour productivity, and the target wage, reflected in the negative relationship between unemployment and the real wage."

Table 3. Wage equations

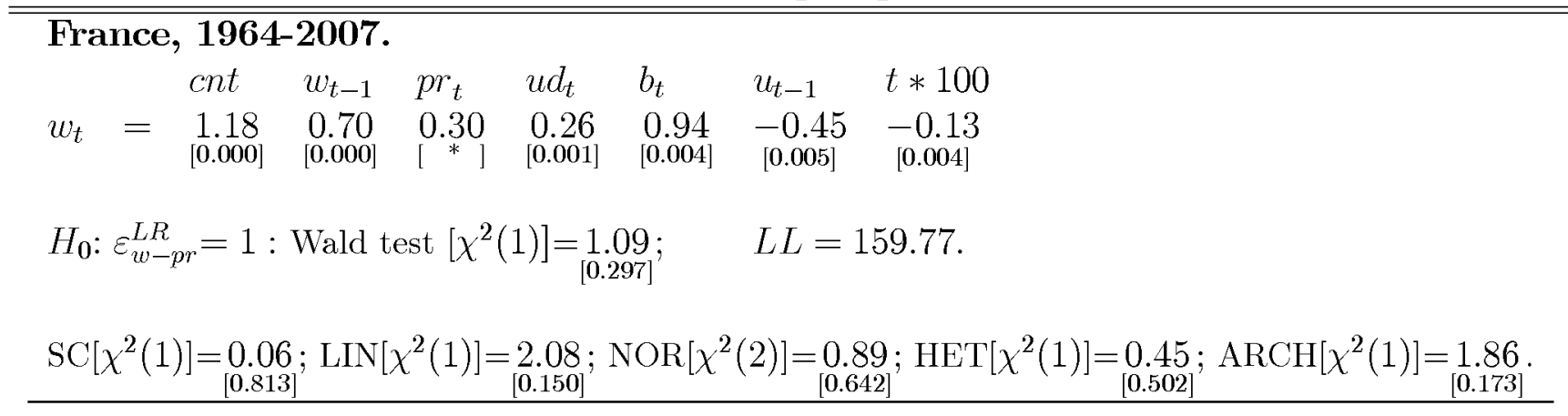

Germany, 1964-2007.

$\begin{array}{cccccccccccc}c n t & w_{t-1} & \Delta w_{t-1} & \Delta w_{t-3} & p r_{t} & u d_{t} & \Delta u d_{t} & b_{t-1} & \tau_{t}^{d} & u_{t} & \Delta u_{t} \\ w_{t}= & 2.41 & 0.40 & 0.33 & 0.29 & 0.60 & 0.09 & 0.29 & 0.19 & 0.70 & -0.36 & 0.74 \\ {[0.000]} & {[0.000]} & {[0.000]} & {[0.000]} & {[*]} & {[0.082]} & {[0.016]} & {[0.151]} & {[0.003]} & {[0.000]} & {[0.000]}\end{array}$

$H_{0}: \varepsilon_{w-p r}^{L R}=1:$ Wald test $\left[\chi^{2}(1)\right]=\underset{[0.274]}{1.20 ;} \quad L L=163.95$.

$\mathrm{SC}\left[\chi^{2}(1)\right]=\underset{[0.986]}{0.00} ; \operatorname{LIN}\left[\chi^{2}(1)\right]=\underset{[0.968]}{0.00} ; \operatorname{NOR}\left[\chi^{2}(2)\right]=\underset{[0.437]}{1.65} ; \operatorname{HET}\left[\chi^{2}(1)\right]=\underset{[0.593]}{0.29} ; \operatorname{ARCH}\left[\chi^{2}(1)\right]=\underset{[0.715]}{0.13}$

Italy, 1962-2007.

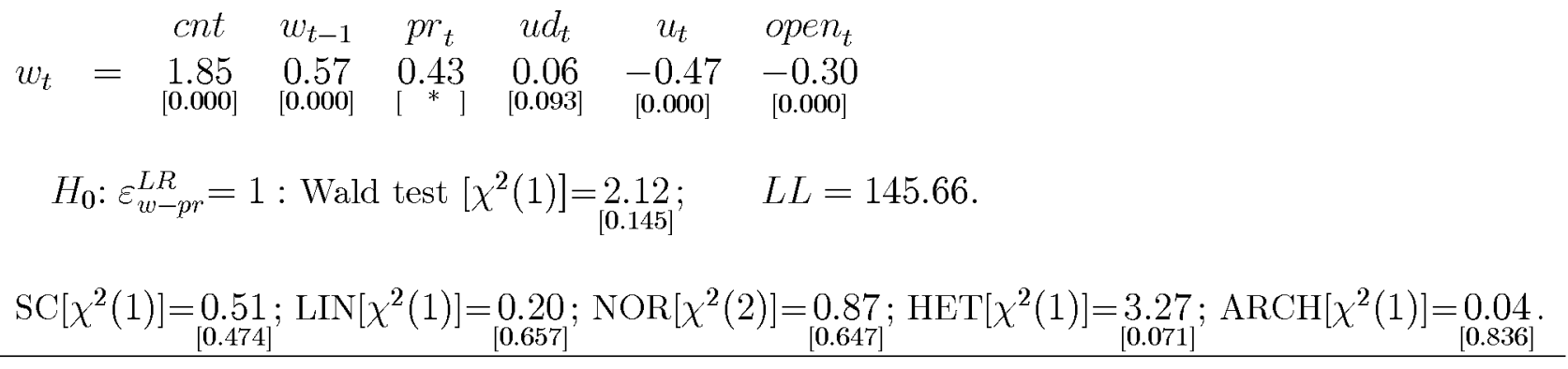




\section{Table 3 (continued)}

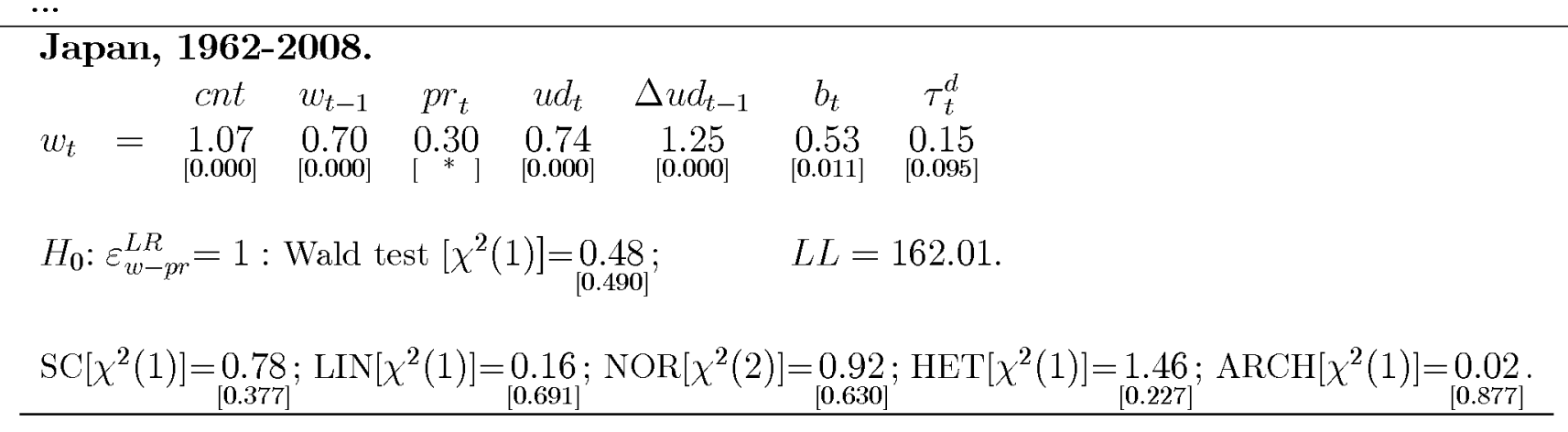

\section{Spain, 1966-2008.}

$\begin{array}{cccccccccc}c n t & w_{t-1} & \Delta w_{t-1} & p r_{t} & b_{t} & w m_{t} & u_{t} & \tau_{t}^{i} & \Delta \tau_{t}^{i} \\ w_{t}= & 3.56 & 0.15 & 0.22 & 0.85 & 0.68 & 0.17 & -0.33 & -1.45 & 1.76 \\ {[0.000]} & {[0.083]} & {[0.023]} & {\left[{ }^{*}\right]} & {[0.003]} & {[0.027]} & {[0.004]} & {[0.000]} & {[0.000]}\end{array}$

$H_{0}: \varepsilon_{w-p r}^{L R}=1:$ Wald test $\left[\chi^{2}(1)\right]=\underset{[0.099]}{2.71} ; \quad L L=147.37$.

$\operatorname{SSC}\left[\chi^{2}(1)\right]=\underset{[0.888]}{0.02} ; \operatorname{LIN}\left[\chi^{2}(1)\right]=\underset{[0.519]}{0.42} ; \operatorname{NOR}\left[\chi^{2}(2)\right]=\underset{[0.731]}{0.63} ; \operatorname{HET}\left[\chi^{2}(1)\right]=\underset{[0.080]}{3.07} ; \operatorname{ARCH}\left[\chi^{2}(1)\right]=\underset{[0.291]}{1.12}$

U.K., 1962-2008.

$\begin{array}{ccccccccc}c n t & w_{t-1} & \Delta w_{t-1} & p r_{t} & u d_{t-1} & \Delta b_{t} & \tau_{t}^{d} & \text { oil } \\ w_{t}= & \begin{array}{ccc}1.83 \\ {[0.000}\end{array} & 0.56 & 0.25 & 0.44 & 0.06 & 1.01 & 0.38 & -0.01 \\ {[0.000]} & {[0.041]} & {\left[{ }^{*}\right]} & {[0.005]} & {[0.003]} & {[0.021]} & {[0.000]}\end{array}$

$H_{0}: \varepsilon_{w-p r}^{L R}=1:$ Wald test $\left[\chi^{2}(1)\right]=\underset{[0.717]}{0.13} ; \quad L L=152.47$.

$\operatorname{SC}\left[\chi^{2}(1)\right]=\underset{[0.909]}{0.01} ; \operatorname{LIN}\left[\chi^{2}(1)\right]=\underset{[0.748]}{0.10} ; \operatorname{NOR}\left[\chi^{2}(2)\right]=\underset{[0.497]}{1.40} ; \operatorname{HET}\left[\chi^{2}(1)\right]=\underset{[0.794]}{0.07} ; \operatorname{ARCH}\left[\chi^{2}(1)\right]=\underset{[0.897]}{0.02}$

U.S., 1962-2007.

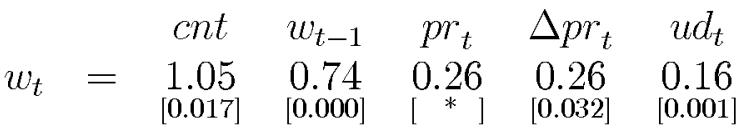

$H_{0}: \varepsilon_{w-p r}^{L R}=1:$ Wald test $\left[\chi^{2}(1)\right]=\underset{[0.405]}{0.69} ; \quad L L=157.75$.

$\operatorname{SC}\left[\chi^{2}(1)\right]=1.95 ; \operatorname{LIN}\left[\chi^{2}(1)\right]=0.79 ; \operatorname{NOR}\left[\chi^{2}(2)\right]=0.33 ; \operatorname{HET}\left[\chi^{2}(1)\right]=1.50 ; \operatorname{ARCH}\left[\chi^{2}(1)\right]=0.00$.

Note: $\Delta$ denotes the difference operator; $p$-values in brackets.

$\left(^{*}\right)$ Restricted coefficient for a long-run unit elasticity between wages and productivity: $\varepsilon_{w-p r}^{L R}=1$.

The following observations can be drawn from Table 3. First, out of the seven countries we examine, wage-push factors have a minimal impact on wage setting in Italy, and a minor one in the US. In particular, (i) the impact of benefits $\left(b_{t}\right)$ has the largest value in France, followed closely by Japan and Spain, while it is modest in Germany, non existent in the US and Italy, and with a transient moving-average feature in the UK; (ii) union 
density $\left(u d_{t}\right)$ is quite influential in Japan and France, has a minor impact in the US, and minimal effects in Germany, Italy, and the UK; (iii) in the absence of a union density effect in Spain, the minimum wage factor $\left(w m_{t}\right)$ acts as a wage-push factor (albeit with a rather small effect). Second, the unemployment rate $\left(u_{t}\right)$ does not put any downward pressure on real wages in the US, UK, and Japan; in these countries the only downward pressure is in the UK from the oil price, oil . Finally, in addition to unemployment, other factors that put downward pressure on wages are openness $\left(\right.$ open $\left._{t}\right)$ in Italy, indirect taxes $\left(\tau_{t}^{i}\right)$ in Spain, and a time trend in France. ${ }^{18}$

\subsection{Labour Demand Estimations}

The estimations shown in Table 4 below are empirical versions of the analytical equation (15) and feature the following elements.

The labour share, $l s_{t}$ (or wage-productivity gap) affects negatively the employment trajectory. Note that both the sign and significance of the wage component of the labour share conform with the requirements of a typical labour demand equation, while the productivity component of the labour share can be seen as embodying the influence of capital stock and technical progress on productivity (Manning, 1993, among others).

It is worthwhile to summarise the ranking of the countries according to the size of the impact of the labour share on employment; the short-run (contemporaneous) and long-run sensitivities are reported in Table 5. Japan and France are at the low end of the spectrum, Spain is at the high end with a large difference from the rest, while Italy, Germany, the UK and US are in intermediate territory. It is interesting to note the change in the ranking when dynamics are taken into account. Although Japan remains at the low end of the spectrum, Europe's largest economies (France, UK and Germany) follow closely with a long-run sensitivity of around one. Notably, Spain is still at the top of the ranking with a value approximately five times higher. The US is right at the middle - the sensitivity of employment to the labour share (2.2) is twice the size of that in the $\mathrm{UK}(1.1)$, and half the size of that in Spain (5.0).

Recall that the dynamic nature of labour demand reflects employment adjustment costs and, thus, the first-order autoregressive coefficients in Table 4 indicate the employment persistence of each country. Although Italy, Germany, UK, and US share similar contemporaneous responses of employment to a change in the labour share (see second row in Table 5), they differ substantially in terms of their employment persistence (see Table 4, coefficient of $\left.n_{t-1}\right)$ : the lowest is in the UK (0.82), followed by Germany (0.85), then the US (0.91), while in Italy persistence is as high as 0.95. Clearly, the disparity between the 'short-run' and 'long-run' rankings in Table 5 is associated with the degree

\footnotetext{
${ }^{18}$ We view this negative trend as capturing some idiosyncratic features of the French economy for which data is not available - possibly related to issues dealing with the importance of public sector employment.
} 
of the countries' employment persistence. In Section 5 we present a detailed evaluation of the labour share contributions to the employment time path during each decade.

Table 4. Employment equations

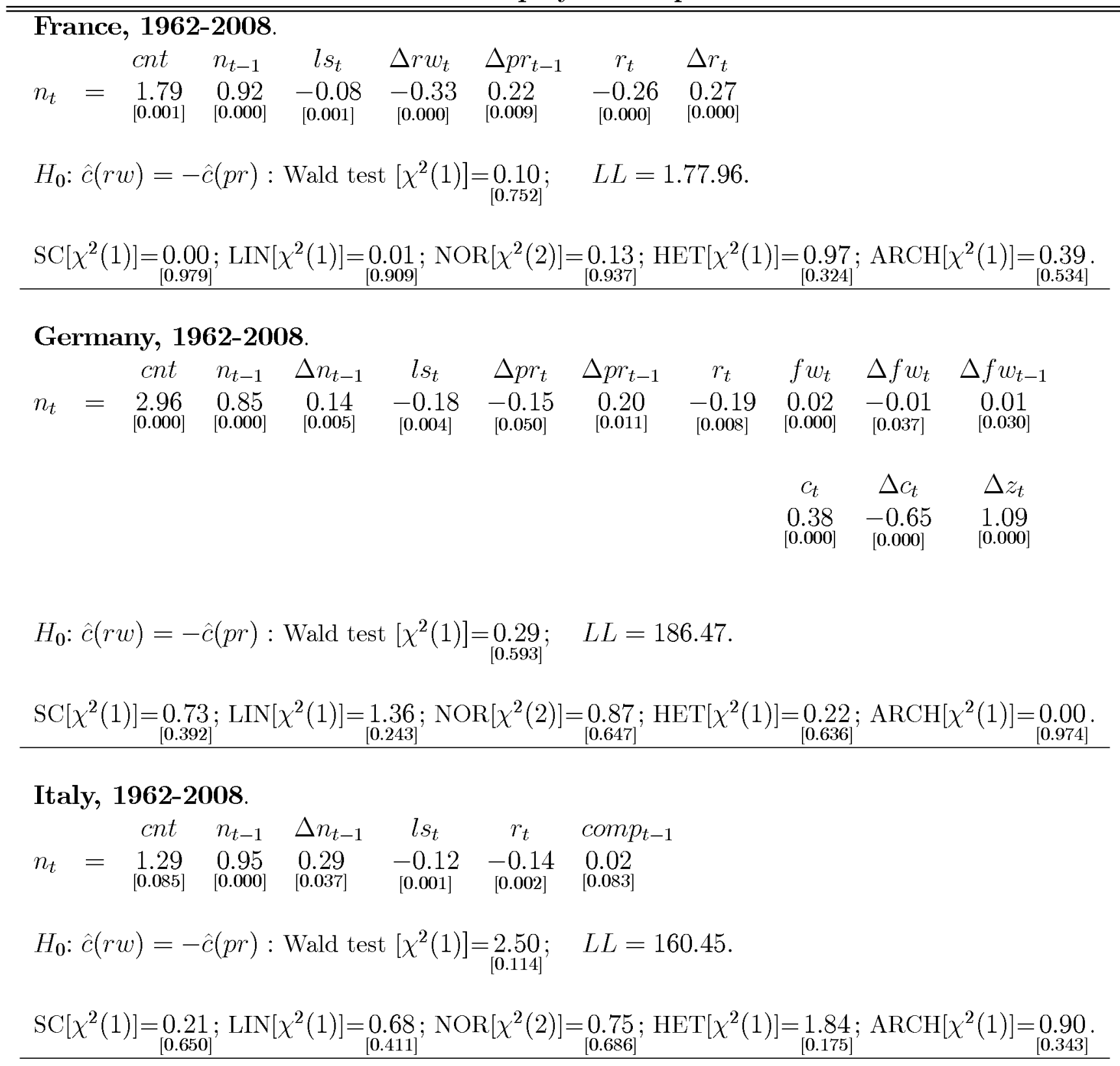




\section{Table 4 (continued)}

\begin{tabular}{|c|c|c|c|c|c|c|c|c|}
\hline \multicolumn{9}{|c|}{ Japan, 1961-2008. } \\
\hline & & $c n t$ & $n_{t-1}$ & $l s_{t}$ & $\Delta r w_{t}$ & $\Delta p r_{t}$ & $r b_{t-1}$ & $t * 100$ \\
\hline$n_{t}$ & $=$ & $\begin{array}{l}0.66 \\
{[0.271]}\end{array}$ & $\begin{array}{c}0.92 \\
{[0.000]}\end{array}$ & $\begin{array}{l}-0.06 \\
{[0.046]}\end{array}$ & -0.24 & {$\left[\begin{array}{c}0.10 \\
{[0.094]}\end{array}\right.$} & $\begin{array}{c}0.03 \\
{[0.001]}\end{array}$ & $\begin{array}{l}-0.18 \\
{[0.000]}\end{array}$ \\
\hline \multicolumn{7}{|c|}{$H_{0}: \hat{c}(r w)=-\hat{c}(p r):$ Wald test $\left[\chi^{2}(1)\right]=\underset{[0.877]}{0.02}$} & \multicolumn{2}{|c|}{$L L=181.85}$. \\
\hline \multicolumn{9}{|c|}{$\operatorname{SC}\left[\chi^{2}(1)\right]=\underset{[0.064]}{3.44} ; \operatorname{LIN}\left[\chi^{2}(1)\right]=\underset{[0.321]}{0.99} ; \operatorname{NOR}\left[\chi^{2}(2)\right]=\underset{[0.310]}{2.34} ; \operatorname{HET}\left[\chi^{2}(1)\right]=\underset{[0.322]}{0.98} ; \operatorname{ARCH}\left[\chi^{2}(1)\right]=\underset{[0.883]}{0.02}$} \\
\hline
\end{tabular}

Spain, 1966-2008.

\begin{tabular}{|c|c|c|c|c|c|c|c|c|c|}
\hline \multirow{3}{*}{$n_{t}=$} & cnt & $n_{t-1}$ & $\Delta n_{t-1}$ & $\Delta n_{t-2}$ & $l s_{t}$ & $r w_{t}$ & $\Delta r w_{t}$ & $\Delta p r_{t}$ & $\Delta p r_{t-2}$ \\
\hline & $\begin{array}{c}2.74 \\
{[0.002]}\end{array}$ & $\begin{array}{c}0.95 \\
{[0.000]}\end{array}$ & $\begin{array}{c}0.64 \\
{[0.000]}\end{array}$ & $\begin{array}{c}-0.29 \\
{[0.074]}\end{array}$ & $\begin{array}{c}-0.25 \\
{[0.015]}\end{array}$ & $\begin{array}{c}-0.05 \\
{[0.007]}\end{array}$ & $\begin{array}{c}-0.26 \\
{[0.064]}\end{array}$ & $\begin{array}{c}-0.34 \\
{[\mathbf{0} .031]}\end{array}$ & $\begin{array}{c}-0.26 \\
{[0.111]}\end{array}$ \\
\hline & & & & & & & $\begin{array}{l}r_{t} \\
-0.15 \\
{[0.023]}\end{array}$ & $\begin{array}{c}o i l_{t} \\
-0.01 \\
{[0.015]}\end{array}$ & $\begin{array}{l}\Delta o i l_{t} \\
0.015 \\
{[\mathbf{0 . 0 3 7}]}\end{array}$ \\
\hline
\end{tabular}

$H_{0}: \hat{c}(r w)=0:$ Wald test $\left[\chi^{2}(1)\right]=\underset{[0.004]}{8.28 ;} \quad L L=140.92$.

$\operatorname{SC}\left[\chi^{2}(1)\right]=2.03 ; \operatorname{LIN}\left[\chi^{2}(1)\right]=2.02 ; \operatorname{NOR}\left[\chi^{2}(2)\right]=0.48 ; \operatorname{HET}\left[\chi^{2}(1)\right]=1.24 ; \operatorname{ARCH}\left[\chi^{2}(1)\right]=0.04$

U.K., 1962-2008.

$\begin{array}{cccccccc}c n t & n_{t-1} & \Delta n_{t-1} & l s_{t} & \Delta p r_{t-1} & r_{t} & c_{t} \\ n_{t}= & 3.71 & 0.82 & 0.54 & -0.20 & 0.29 & -0.13 & 0.28 \\ {[0.000]} & {[0.000]} & {[0.000]} & {[0.001]} & {[0.002]} & {[0.019]} & {[0.001]}\end{array}$

$H_{0}: \hat{c}(r w)=-\hat{c}(p r):$ Wald test $\left[\chi^{2}(1)\right]=\underset{[0.690]}{0.16} ; \quad L L=166.03$

$\operatorname{SC}\left[\chi^{2}(1)\right]=2.03 ; \operatorname{LIN}\left[\chi^{2}(1)\right]=2.01 ; \operatorname{NOR}\left[\chi^{2}(2)\right]=3.96 ; \operatorname{HET}\left[\chi^{2}(1)\right]=1.66 ; \operatorname{ARCH}\left[\chi^{2}(1)\right]=0.48$

U.S., 1962-2008.

$n_{t}=\begin{array}{ccccccc}c n t & n_{t-1} & l s_{t} & r w_{t} & r b_{t} & \Delta r b_{t} & \Delta r b_{t-1} \\ 1.98 & 0.91 & -0.20 & -0.12 & 0.08 & -0.16 & 0.18 \\ {[0.028]} & {[0.000]} & {[0.076]} & {[\mathbf{0 . 0 7 2}]} & {[\mathbf{0 . 0 6 5}]} & {[\mathbf{0 . 0 1 0}]} & {[\mathbf{0 . 0 0 8}]}\end{array}$

$H_{0}: \hat{c}(r w)=0:$ Wald test $\left[\chi^{2}(1)\right]=\underset{[0.65]}{3.41} ; \quad L L=152.62$

$\mathrm{SC}\left[\chi^{2}(1)\right]=1.35 ; \operatorname{LIN}\left[\chi^{2}(1)\right]=1.92 ; \operatorname{NOR}\left[\chi^{2}(2)\right]=0.39 ; \operatorname{HET}\left[\chi^{2}(1)\right]=0.17 ; \operatorname{ARCH}\left[\chi^{2}(1)\right]=0.43$.

Note: $\Delta$ denotes the difference operator; p-values in brackets.

$\hat{c}(r w)$ and $\hat{c}(p r)$ are, respectively, the estimated coefficients on real wages and labour productivity.

Furthermore, real interest rates, $r_{t}$, or real balances, $r b_{t}$, with the expected negative and positive effects, respectively, are among the determinants of labour demand capturing 
the influence of monetary conditions on employment. ${ }^{19}$ These effects can be seen as evidence against the classical dichotomy of a vertical Phillips curve; for example, as Ball and Mankiw (2002, p. 116) point out "belief that monetary policy has employment effects is inextricably tied to belief in the inflation-unemployment tradeoff."

Finally note that our estimations identified as employment determinants (i) the aggregate demand factors of financial wealth, $f w_{t}$, and private consumption, $c_{t}$, and (ii) the input price factors of oil prices, $o i l_{t}$, and competitiveness, comp , all with the expected signs. $^{20}$

Table 5. Labour income share sensitivities

\begin{tabular}{lccccccc}
\hline & Japan & France & Italy & Germany & UK & US & Spain \\
\cline { 2 - 8 } short-run & 0.06 & 0.08 & 0.12 & 0.18 & 0.20 & 0.20 & 0.25 \\
long-run & 0.75 & 1.0 & 1.1 & 1.2 & 2.2 & 2.4 & 5.0 \\
\hline
\end{tabular}

\section{Employment Contributions of the Labour Share}

In what follows we analyse the conceptual underpinnings of what we call contributions and present the empirical evidence of the contributions of the labour share to the employment trajectory.

\subsection{Dynamic Contributions: Conceptual Underpinnings}

One of the salient features of our dynamic modelling approach is that we define an impulse, or "shock" as a one-off change in a specific exogenous variable. Defining the impulse (shock) as a change in an exogenous variable, rather than as a one-off change in the residuals of a behavioural equation, ${ }^{21}$ has a clear advantage: it gives rise to 'dynamic contributions', a measure that shows how the endogenous variable of a dynamic equation responds to the actual changes in an exogenous variable over a sample interval.

The most pedagogical illustration of the concept of dynamic contributions can be given in the context of a simple $\mathrm{AR}(1)$ employment equation:

$$
n_{t}=\alpha n_{t-1}+\beta x_{t}, \text { where }|\alpha|<1 .
$$

The impulse response function (IRF) of the stochastic process (28) to a one-off unit change

\footnotetext{
${ }^{19}$ Among other studies, Pissarides (1991) finds that the real interest rate and M3 have significant employment effects in the Australian labour market over the 1966-86 period.

${ }^{20}$ The influence of aggregate demand and input price factors on employment is also a feature of the labour demand function in Manning (1993, equation (2)).

${ }^{21}$ Blanchard (2009, p. 220) correctly points out that "The use of "shocks" is fraught with philosophical, but also with practical, difficulties: Technological shocks, animal spirits, changes in perceived uncertainty, etc. all have deeper causes, which themselves have even deeper causes, and so on."
} 
in the exogenous variable $x_{t}$ is

IRF of the $\mathrm{AR}(1):$\begin{tabular}{|c|c|c|c|c|c|c|}
\hline time & $t$ & $t+1$ & $t+2$ & $\ldots$ & $t+10$ & $\ldots$ \\
\hline responses & $\beta$ & $\beta \alpha$ & $\beta \alpha^{2}$ & $\ldots$ & $\beta \alpha^{10}$ & $\ldots$ \\
\hline
\end{tabular}

Note that a one-time unit shock will have an immediate unit $\times \beta$ impact on employment, while the future effects of the shock decline in a geometric fashion. We can summarise the sensitivity of employment with respect to variable $x$ as:

$$
\begin{aligned}
& \text { long-run sensitivity }=\text { short-run sensitivity }+ \text { persistence }, \\
& \beta /(1-\alpha) \quad \beta \quad \beta \alpha /(1-\alpha)
\end{aligned}
$$

where employment persistence is defined as the sum of future responses (i.e. the responses in the aftermath of the shock), short-run sensitivity refers to the contemporaneous response, and the long-run sensitivity is given by the sum of all responses.

On the basis of the above analysis, we measure the contributions of the exogenous variable $x$ to the evolution of employment over a specific period of time, say $t=1$ to $t=T$, by sequentially adding up the IRFs of the respective changes during the specific period. Let $\Delta x_{j}=x_{j}-x_{j-1}$, where $j=1,2, \ldots T$, and $\Delta$ is the first difference operator. The IRFs of these $T$ shocks are:

$$
\left[\begin{array}{ccccc} 
& t=1 & t=2 & \ldots & t=T \\
\mathrm{IRF}_{1}: & R_{11} & R_{12} & \ldots & R_{1 T} \\
\mathrm{IRF}_{2}: & - & R_{22} & \ldots & R_{2 T} \\
\ldots & - & - & \ldots & \ldots \\
\mathrm{IRF}_{T}: & - & - & \ldots & R_{T T}
\end{array}\right]
$$

where $\mathrm{IRF}_{j}$ denotes the response function of employment to the $j$ th shock, and $R_{j t}$ is the response to shock $j$ in time $t$. Note that the diagonal elements in matrix (31) denote the respective contemporaneous employment response to the $j$ th one-off shock, whereas the elements above the diagonal denote the employment responses in period $t$ to the shocks which occurred in the past $j$ periods. Therefore, the $t$-period contribution can be obtained as the sum of all responses in this period.

In other words, the contributions of the exogenous variable $x$ to the employment trajectory for the given interval are given by the following time series:

$$
\begin{array}{ccccc}
t=1 & t=2 & t=3 & \ldots & t=T \\
R_{11}, & \sum_{j=1}^{2} R_{j 2}, & \sum_{j=1}^{3} R_{j 3}, & \ldots & \sum_{j=1}^{T} R_{j T} .
\end{array}
$$




\subsection{Empirical Contributions}

Although sensitive to business cycle variations, employment is an overall growing variable. For all countries in our sample the number of jobs has generally grown across decades (there are only three exceptions - Spain in the 1970s, Italy in the 1990s, and Japan in the $2000 \mathrm{~s}$ ). In contrast, the labour share has followed a downward path for the last three decades in every country with just two exceptions - the UK in the eighties, and Italy in the noughties. The analysis in Section 3 and the empirical results in Section 4 show that the wage gap affects labour demand negatively. Put differently, the falling labour shares led to higher employment levels. Below we explain how we can measure the employment contributions of the wage gap.

For each of the seven countries in our sample, we examine the influence of the labour share on the employment trajectory over the periods 1970-1980, 1980-1990, 1990-2000, and 2000-2008 by carrying out counterfactual simulations and applying the technique described in the previous section. We evaluate the contributions of the labour share by plotting the actual series of employment against its simulated series obtained by fixing - in the estimations of Table 4 - the labour share at its value at the start of a specific period. The disparity between the actual and simulated series of employment measures the dynamic contribution of the wage gap to employment for the specific period. The actual changes in employment, and the employment contributions of the labour income share are given in Table 6 , whereas the actual and simulated employment trajectories are portrayed in the second column of Figures A.2-8 in the Appendix (blue and red lines, respectively). Note that the actual and fixed values of the labour share are plotted in the first column of Figures A.2-8 (blue and red lines, respectively).

As an example consider France in the seventies. The question to be answered is "Had the labour share remained at $73.9 \%$, i.e. at its 1970 value, what would have been the employment level in 1980?" The distance between the blue and red lines in Figure A.2a measures the cumulation of "shocks" experienced in each year; by 1980 the magnitude of the labour share shocks was 4.3 percentage points ( $\left.l s\right|_{70} ^{80}=4.3 \mathrm{pp}$ in Table 6$)$. In turn, the distance between the blue and red lines in Figure A.2b measures the dynamic contributions of the labour share to the employment time path. In this case we find that, because the labour share rose by $4.3 \mathrm{pp}$, the French economy failed to increase employment by $2.1 \%$, i.e. it was unable to create 0.49 million jobs out of 23.31 millions that would result in the absence of the "shock" (i.e. we subtract the 1980 values of the blue and red lines in Figure A.2b: $22.8-23.31=-0.49$ millions or $\frac{-0.49}{23.31}=-2.1 \%$ ). In other words, the contribution of the change in the labour share to the employment trajectory during the seventies is $\left.n\right|_{70} ^{80}=-2.1 \%$ (see also Table 6 ). To gauge the significance of this contribution, Table 6 also reports the actual increase in employment over the seventies, $\Delta n_{70 \rightarrow 80}=6.5 \%$. (Note that all the information presented in Table 6 can be retrieved 
from Figures A.2-8.)

Table 6. Employment contributions of the labour income share

\begin{tabular}{|c|c|c|c|c|c|c|c|}
\hline & France & Germany & Italy & Japan & Spain & UK & US \\
\hline $\begin{array}{l}1970 \mathrm{~s} \\
\Delta n_{70 \rightarrow 80}\end{array}$ & $6.5 \%$ & $3.1 \%$ & $7.0 \%$ & $8.7 \%$ & $-3.9 \%$ & $1.4 \%$ & $22.0 \%$ \\
\hline$\left.l s\right|_{70} ^{80}$ & $4.3 \mathrm{pp}$ & $2.0 \mathrm{pp}$ & $0.4 \mathrm{pp}$ & $8.7 \mathrm{pp}$ & $-0.4 \mathrm{pp}$ & $-0.7 \mathrm{pp}$ & $-2.2 \mathrm{pp}$ \\
\hline$\left.n\right|_{70} ^{80}$ & $\begin{array}{c}-2.1 \% \\
\left(=\frac{-0.49}{23.31}\right) \\
\end{array}$ & $\begin{array}{l}-2.4 \% \\
\left(=\frac{-0.67}{28.09}\right) \\
\end{array}$ & $\begin{array}{c}-2.4 \% \\
\left(=\frac{-0.52}{21.25}\right) \\
\end{array}$ & $\begin{array}{c}-5.3 \% \\
\left(=\frac{-3.10}{58.46}\right) \\
\end{array}$ & $\begin{array}{c}3.7 \% \\
\left(=\frac{0.46}{12.45}\right) \\
\end{array}$ & $\begin{array}{c}4.8 \% \\
\left(=\frac{1.16}{23.93}\right) \\
\end{array}$ & $\begin{array}{c}3.4 \% \\
\left(=\frac{3.33}{99.30}\right) \\
\end{array}$ \\
\hline $\begin{array}{l}\text { 1980s } \\
\Delta n_{80 \rightarrow 90}\end{array}$ & $2.0 \%$ & $10.9 \%$ & $1.4 \%$ & $12.9 \%$ & $8.9 \%$ & $7.1 \%$ & $19.6 \%$ \\
\hline$\left.l s\right|_{80} ^{90}$ & $-8.7 \mathrm{pp}$ & $-6.0 \mathrm{pp}$ & $-5.4 \mathrm{pp}$ & $-7.6 \mathrm{pp}$ & $-4.9 \mathrm{pp}$ & $0.5 \mathrm{pp}$ & $-2.8 \mathrm{pp}$ \\
\hline$\left.n\right|_{80} ^{90}$ & $\begin{array}{c}6.9 \% \\
\left(=\frac{1.5}{21.63}\right) \\
\end{array}$ & $\begin{array}{c}6.9 \% \\
\left(=\frac{1.96}{28.45}\right) \\
\end{array}$ & $\begin{array}{c}6.4 \% \\
\left(=\frac{1.26}{19.76}\right) \\
\end{array}$ & $\begin{array}{l}2.9 \% \\
\left(=\frac{1.77}{60.72}\right) \\
\end{array}$ & $\begin{array}{l}11.3 \% \\
\left(=\frac{1.33}{11.73}\right) \\
\end{array}$ & $\begin{array}{l}-0.7 \% \\
\left(=\frac{-0.18}{26.69}\right) \\
\end{array}$ & $\begin{array}{c}3.4 \% \\
\left(=\frac{3.93}{114.87}\right) \\
\end{array}$ \\
\hline $\begin{array}{l}1990 \mathbf{s} \\
\Delta n_{90 \rightarrow 00}\end{array}$ & $4.7 \%$ & $2.8 \%$ & $-0.7 \%$ & $3.2 \%$ & $19.6 \%$ & $2.3 \%$ & $15.2 \%$ \\
\hline$\left.l s\right|_{90} ^{00}$ & $-2.7 \mathrm{pp}$ & $-1.5 \mathrm{pp}$ & $-6.6 \mathrm{pp}$ & $-1.2 \mathrm{pp}$ & $-0.6 \mathrm{pp}$ & $-2.8 \mathrm{pp}$ & $-1.8 \mathrm{pp}$ \\
\hline$\left.n\right|_{90} ^{00}$ & $\begin{array}{l}1.5 \% \\
\left(=\frac{0.35}{23.87}\right)\end{array}$ & $\begin{array}{c}3.0 \% \\
\left(=\frac{1.15}{37.99}\right) \\
\end{array}$ & $\begin{array}{r}8.8 \% \\
\left(=\frac{1.68}{19.20}\right) \\
\end{array}$ & $\begin{array}{c}0.3 \% \\
\left(=\frac{0.22}{64.24}\right) \\
\end{array}$ & $\begin{array}{c}0.7 \% \\
\left(=\frac{0.11}{15.51}\right) \\
\end{array}$ & $\begin{array}{c}7.6 \% \\
\left(=\frac{1.93}{25.55}\right) \\
\end{array}$ & $\begin{array}{c}4.1 \% \\
\left(=\frac{5.41}{131.49}\right) \\
\end{array}$ \\
\hline $\begin{array}{l}2000 \mathrm{~s} \\
\Delta n_{00 \rightarrow 08}\end{array}$ & $7.0 \%$ & $2.9 \%$ & $10.9 \%$ & $-0.9 \%$ & $29.7 \%$ & $7.1 \%$ & $6.2 \%$ \\
\hline$\left.l s\right|_{00} ^{08}$ & $-0.1 \mathrm{pp}$ & $-3.8 \mathrm{pp}$ & $1.3 \mathrm{pp}$ & $-4.3 \mathrm{pp}$ & $-1.4 \mathrm{pp}$ & $-2.1 \mathrm{pp}$ & $-1.1 \mathrm{pp}$ \\
\hline$\left.n\right|_{00} ^{08}$ & $\begin{array}{c}0.3 \% \\
\left(=\frac{0.08}{25.83}\right)\end{array}$ & $\begin{array}{c}4.7 \% \\
\left(=\frac{1.82}{38.46}\right)\end{array}$ & $\begin{array}{c}-1.1 \% \\
\left(=\frac{-0.26}{23.42}\right)\end{array}$ & $\begin{array}{c}2.4 \% \\
\left(=\frac{1.47}{62.38}\right)\end{array}$ & $\begin{array}{c}1.9 \% \\
\left(=\frac{0.38}{19.88}\right)\end{array}$ & $\begin{array}{c}2.6 \% \\
\left(=\frac{0.74}{28.70}\right)\end{array}$ & $\begin{array}{c}1.2 \% \\
\left(=\frac{1.70}{143.67}\right)\end{array}$ \\
\hline
\end{tabular}

Note: $\Delta n_{x \rightarrow y}$ and $\left.l s\right|_{x} ^{y}$ denote, respectively, actual changes in employment (in \%) and labour income shares (in pp) between indicated dates, $x$ and $y$; in turn, $\left.n\right|_{x} ^{y}$ denotes the contribution in that period (in \%, ratio in millions) of the labour income share to the evolution of employment.

During the 1970s, the increase in the labour share in France, Germany, and Italy (ls $\left.\right|_{70} ^{80}$ in Table 6) contributed negatively to employment, between $-2 \%$ and $-2.5 \%$. This result supports the viewpoint of Bruno and Sachs (1985) that the excessive warranted wage vis-à-vis the productivity slowdown was an important factor of the unemployment 
increase. This also seems to be especially true in Japan, where the relatively large increase in the labour share $(8.7 \mathrm{pp})$ accounts for a $5.3 \%$ decrease in employment. In contrast, in Spain, the UK, and US the fall in the labour share had a significant positive contribution to employment. It is worth noting that although the labour share fall in Spain and the UK was just a small fraction of that in the US, its employment contribution was larger than in the US. Specifically, in Spain, the relatively small fall in the labour share was an important break to the employment decrease; in the absence of such a break, the rate of change in the reduction of employment would have been double its actual size.

The picture changes dramatically in the eighties as all countries (except the UK) experience large drops in their labour shares, about 2-3 times larger than the one in the US. In Japan the abrupt change is dramatic with the labour share moving from an $8.7 \mathrm{pp}$ increase, the highest value in the sample, down to a $7.6 \mathrm{pp}$ decrease from the 1970 s to the 1980s. Nevertheless, its employment contribution is disappointingly small when compared to that in the US and the continental European countries. Also in sharp contrast to the seventies, the French labour share fell by 8.7 pp in the eighties, contributing 1.5 million jobs or $6.9 \%$ more employment.

All labour shares continued to fall in the roaring nineties. Although France and the UK faced similar drops in their labour shares (-2.7 and $-2.8 \mathrm{pp})$, the employment contribution in the UK is five times higher than the respective one in France. The highest value of the employment contribution relative to its labour share change (in absolute terms) is observed in the UK $(7.6 / 2.8=2.7)$ followed by the ones in the US and Germany. It is worth pointing out that, while Germany and Japan experienced a similar slowdown in their falling labour shares, the significant employment contribution in post unification Germany is starkly different from the minimal employment contribution witnessed in Japan during its 'lost decade'.

Labour shares continued to fall well into the noughties in most countries; the exceptions are two countries of the Eurozone, Italy with an increase and France with a minimal fall. In particular, following the introduction of the euro, Germany experienced the largest drop among the EMU countries, a drop that was higher than that of the Anglo-Saxon economies. Although Germany had the second largest reduction after Japan, it witnessed the highest employment contribution with a value of $4.7 \%$, double the size of that in Japan. Observe that this high value of the employment contribution is matched (in relative terms) by Spain and the Anglo-Saxon economies: the employment contribution relative to the absolute value of its labour share change is

$$
\text { Spain: } \frac{1.9}{|-1.4|}=1, \quad \text { Germany: } \frac{4.7}{|-3.8|}=1.2, \quad \text { UK: } \frac{2.6}{|-2.1|}=1.2, \quad \text { US: } \frac{1.2}{|-1.1|}=1.1 .
$$

According to our findings, the larger the decrease in the labour share the larger its 
employment contribution. This can be clearly seen by plotting the changes in each country's labour share per decade against their associated employment contributions. This scatter diagram is pictured in Figure 4, while the correlation coefficient between the two magnitudes is as high as $-0.81 .^{22}$ Note that most of the values corresponding to the eighties (five out of seven countries) are towards the bottom-right end of the plot, indicating that this was the decade with the largest reductions in the labour share. In contrast, France, Germany, Italy, and especially Japan witnessed increases in their labour shares in the seventies; thus, datapoints F7, G7, I7, and J7 are towards the top-left end of the plot in Figure 4.

Figure 4. Changes in the labour share and employment contributions

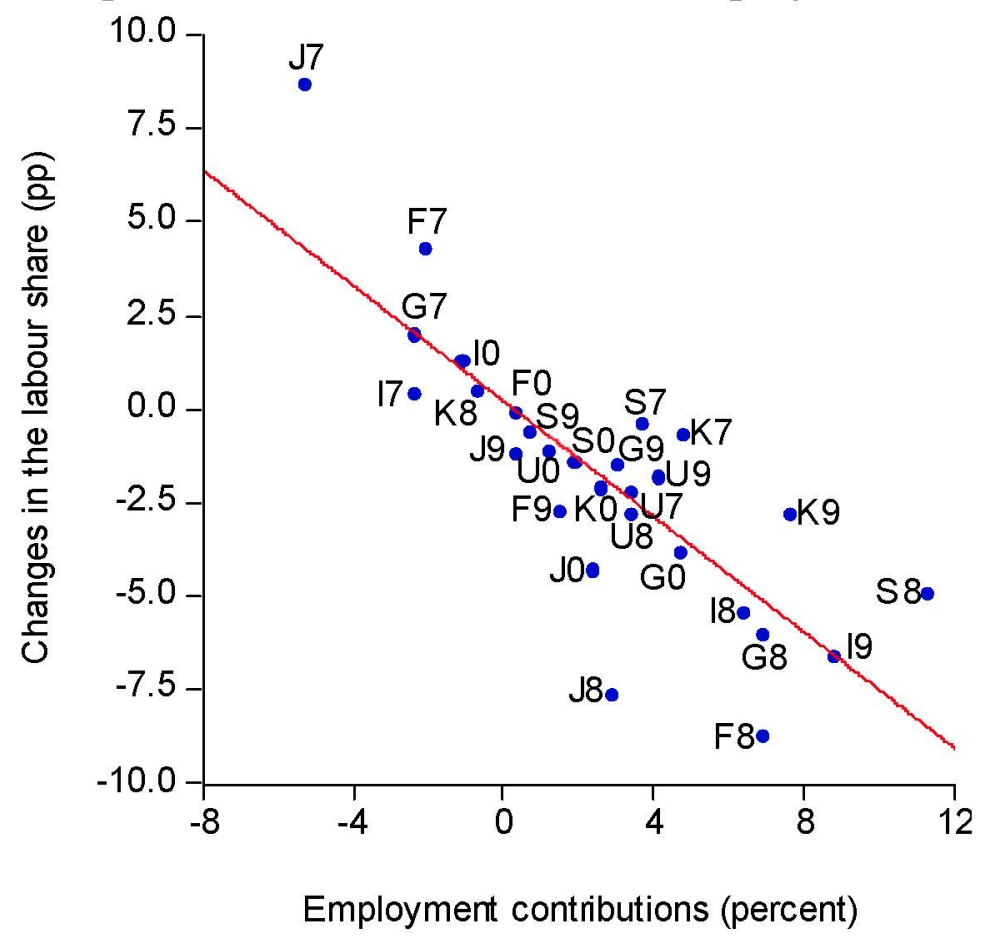

\section{Conclusions}

Whilst maintaining the classical assumption of a one-to-one relationship between real wages and productivity in the long run, this paper challenges the established view that the labour income share is innocuous to employment.

First, using data for France, Germany, Italy, Japan, Spain, the UK, and the US from 1960 to 2008 it is evident that, although widely assumed in the literature, the theoretical property of a constant labour share is strongly refuted by reality.

Second, we argued that the familiar neoclassical world view, i.e. higher productivity is reflected fully in higher real wages, can only prevail in the absence of dynamics and

\footnotetext{
${ }^{22}$ In terms of notation, the country is denoted by its first letter and the decade by its first number (e.g. $\mathbf{J} 7$ denotes Japan in the seventies). The UK is denoted by K, the US by U, and the 2000s by 0 .
} 
growth. The analytical exposition in Section 3 showed that the introduction of dynamics into wage setting distorts this neoclassical wisdom in the short run, while the presence of both wage dynamics and growth rejects it in the long run. In particular, we demonstrated that the interplay of lags and growth, what we call frictional growth, accounts for the disparity between the steady-state wage setting and its long-run state. Put differently, the wage-productivity gap does not vanish in the long run; instead, it is equal to frictional growth. Furthermore, we showed that an implication of frictional growth is that the wageproductivity gap has an influential role in employment dynamics at all time horizons.

Third, we estimated wage setting and labour demand equations for each of the seven countries in our sample and found that the labour share (or wage-productivity gap) affects negatively employment. Ranking the countries according to the size of the impact of the labour share on employment we noted that Japan is at the low end of the spectrum, followed closely by Europe's largest economies (France, Germany, and UK), while Spain is at the top of the ranking with a value approximately five times higher. The US is right at the middle with a sensitivity of employment to the labour share double the size of that in the UK, and half the size of that in Spain.

Finally, we evaluated the contributions of the labour share to the evolution of employment over the seventies, eighties, nineties, and the naughties by carrying out counterfactual simulations. During the 1970s, the increase in the labour share in France, Germany, Italy, and Japan contributed negatively to their employment levels. This result is in line with the once prominent viewpoint that the excessive warranted wage vis-à-vis the productivity slowdown was an important factor of the unemployment increase. However, this picture changed dramatically in the 1980s; almost all countries experienced large drops in their labour shares, contributing positively to employment. The same pattern characterised the 1990s and the 2000s: wages continued to trail productivity (i.e. the labour share continued to fall), and this promoted employment gains.

As our findings clearly indicate that the larger the decrease in the labour share the larger its employment boost, the evolution of the wage-productivity gap should play an instrumental role in policy making. As far as policy making is concerned, it is worth recording that a bird's eye view of academic and press articles highlight the surge in income inequality over the recent decades. Although an investigation of the apparent association of the falling labour share with the increasing inequality was beyond the scope of this paper, we endeavour to address the globalised employment/income inequality mix in future work.

\section{References}

[1] Antràs, P. (2004): "Is the U.S. Aggregate Production Function Cobb-Douglas? New estimates of the Elasticity of Substitution", Contributions to Macroeconomics, vol. 4 (1), 
Article 4 .

[2] Ball, L. and Moffitt, R. (2002): "Productivity growth and the Phillips curve" in A. Krueger and R. Solow (eds.), The Roaring Nineties: Can Full Employment Be Sustained?, Russell Sage Foundation, New York.

[3] Bental, B. and Demouguin, D. (2010): "Declining labor shares and bargaining power: An institutional explanation", Journal of Macroeconomics, vol. 32, pp. 443-456.

[4] Bentolila, S. and Saint-Paul, G. (2003): "Explaining movements in the labor share", Contributions to Macroeconomics, vol. 3 (1), Article 9.

[5] Blanchard, O.J. (2006): "European Unemployment", Economic Policy, January, pp. 6-59.

[6] Blancard, O.J. (2009): "The State of Macro", Annual Review of Economics, vol. 1, pp. 209-228.

[7] Blanchard, O.J. and Katz, L.F. (1999): "Wage dynamics: reconciling theory and evidence", AEA Papers and Proceedings, vol. 89 (2), pp. 69-74.

[8] Blanchflower, D. and Oswald, A. (1994): "The wage curve", MIT Press, Cambridge MA.

[9] Bourguignon, F. and Morrisson, C. (2002): "Inequality Among World Citizens: 1820-1992", The American Economic Review, vol. 92, pp. 727-744.

[10] Bruno, M. and Sachs, J. (1985): "The Economics of Worldwide Stagflation", Basil Blackwell, Oxford.

[11] Cohen A.J and Harcourt, G.C. (2003): "Whatever Happened to the Cambridge Capital Theory Controversies?", Journal of Economic Perspectives, vol. 17, pp. 199-241.

[12] Edward, P. (2006): "Examining Inequality: Who Really benefits from Global Growth?", World Development, vol. 34, pp. 1667-1695.

[13] Galí, J. (2010): "The return of the wage Phillips curve", NBER Working Paper No. 15758, Cambridge: MA.

[14] Gollin, D. (2002): "Getting Income Shares Right", The Journal of Political Economy, vol. 110 (2), pp. 458-474.

[15] Grubb D., R. Jackman, and Layard R. (1982): "Causes of the current stagflation," Review of Economic Studies, vol. 49 (5), pp. 707-730.

[16] Hatton, T.J. (2007): "Can Productivity Growth Explain the NAIRU? Long-Run Evidence from Britain, 1871-1999", Economica, vol. 74, pp. 475-491.

[17] IMF (2007): "The globalization of labor", World Economic Outlook, April, IMF: Washington.

[18] Layard, R., Nickell, S.J., and Jackman, R. (1991): "Unemployment: Macroeconomic Performance and the Labour Market", Oxford University Press, Oxford.

[19] Llense, F. (2010): "French CEOs' compensations: What is the cost of a mandatory upper limit?", CESifo Economic Studies, vol. 56 (2), pp. 165-191.

[20] Manning, A. (1993): "Wage bargaining and the Phillips curve: the identification and specification of aggregate wage equations", The Economic Journal, vol. 103, pp. 98-118.

[21] Moriguchi, C. (2010): "Top wage incomes in Japan, 1951-2005", The Journal of the Japanese and International Economies, vol. 32 (1), pp. 492-496.

[22] OECD (1994): The OECD Jobs Study, Organisation for Economic Co-operation and Development, Paris.

[23] Pesaran, M.H. (1997): "The Role of Economic Theory in Modelling the Long-run", The Economic Journal, 107 (440), pp. 178-191. 
[24] Pesaran, M.H. and Shin, Y. (1999): “An Autoregressive Distributed-Lag Modelling Approach to Cointegration Analysis" in Econometrics and Economic Theory in the Twentieth Century: The Ragnar Frisch Centennial Symposium, edited by Strom, S., Cambridge University Press, pp. 371-413.

[25] Pesaran, M.H., Y. Shin, and Smith, R.J. (2001): "Bounds testing approaches to the analysis of level relationships", Journal of Applied Econometrics, vol. 16, pp. 289-326.

[26] Phelps, E. and Zoega, G. (2001): "Structural booms: productivity expectations and asset valuations", Economic Policy, vol. 32, April, pp. 85-126.

[27] Piketty, T. and Saez, E. (2006): "The Evolution of Top Incomes: A Historical and International Perspective", The American Economic Review, vol. 96, 200-205.

[28] Pissarides, C.A. (1991): "Real Wages and Unemployment in Australia", Economica, vol. 58, pp. 35-55.

[29] Taylor, J.B. (1979: "Staggered wage setting in a macro model", The American Economic Review vol. 69, pp. 108-113.

[30] Taylor, J.B. (1980): "Aggregate dynamics and staggered contracts", Journal of Political Economy vol. 88, pp. 1-23.

[31] Wolff, E.N. and Zacharias, A. (2006): "Wealth and Income Inequality: Who's at the Top of the Economic Ladder?", The Levy Economics Institute of Bard College, LIMEW Report, December 2006.

\section{Appendix}

Table A.1 Testing the long-run relationships in the Johansen framework

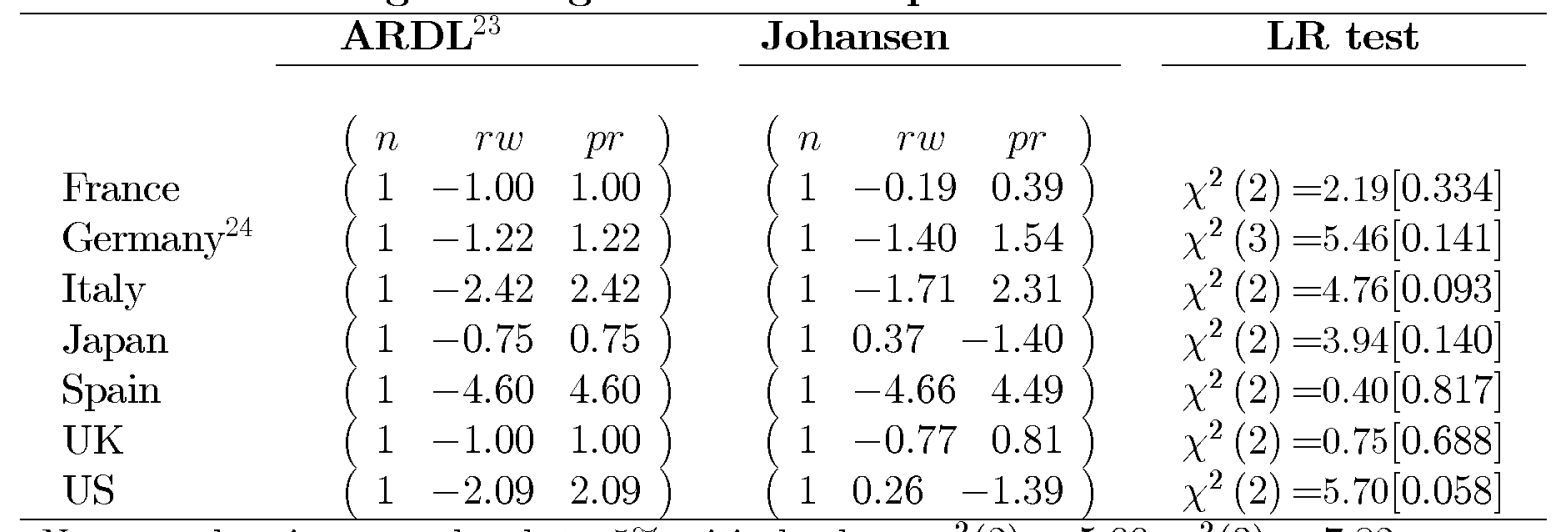

Note: $p$-values in square brackets; $5 \%$ critical values: $\chi^{2}(2)=5.99 ; \chi^{2}(3)=7.82$.

\footnotetext{
${ }^{23}$ Any dicrepancies between these values and those in Table 5 are due to rounding up.

${ }^{24}$ Since financial wealth is $I(1)$, it is included as a fourth variable in the cointegrating vector and, thus, the LR test follows a $\chi^{2}(3)$ distribution. Also note that the long-run coefficient of financial wealth is 0.15 when the ARDL approach is used, and 0.16 according to the Johansen procedure.
} 
Figure A.1 Actual and fitted values

a. France

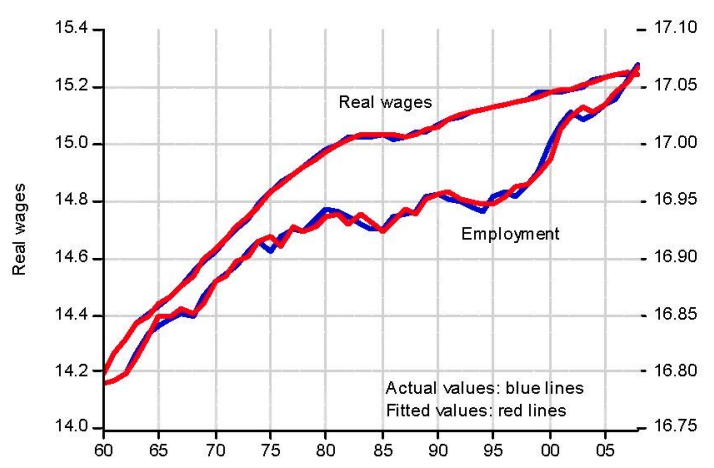

c. Italy

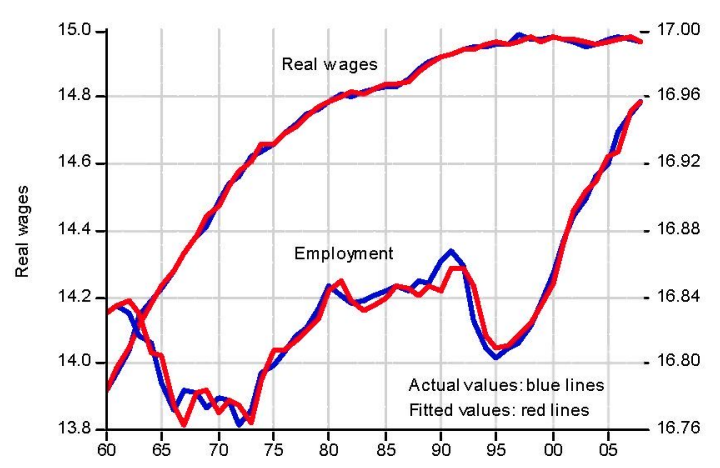

e. Spain

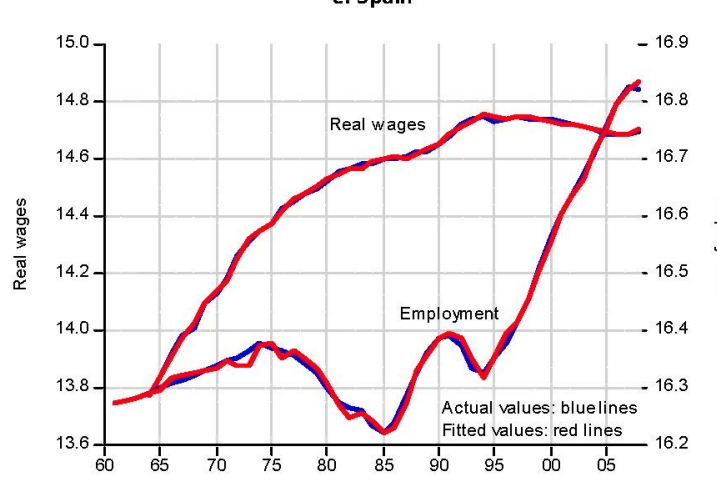

g. U.S.

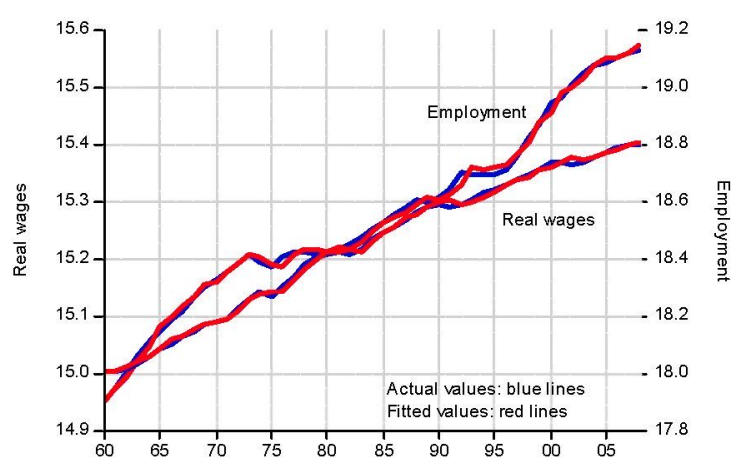

b. Germany

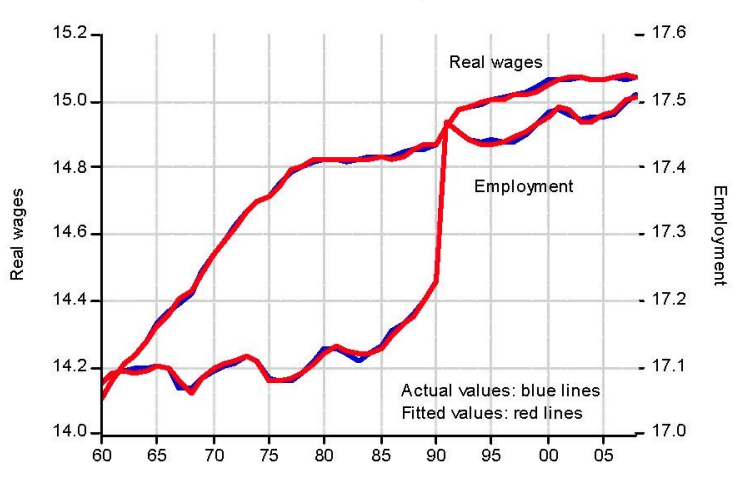

d. Japan

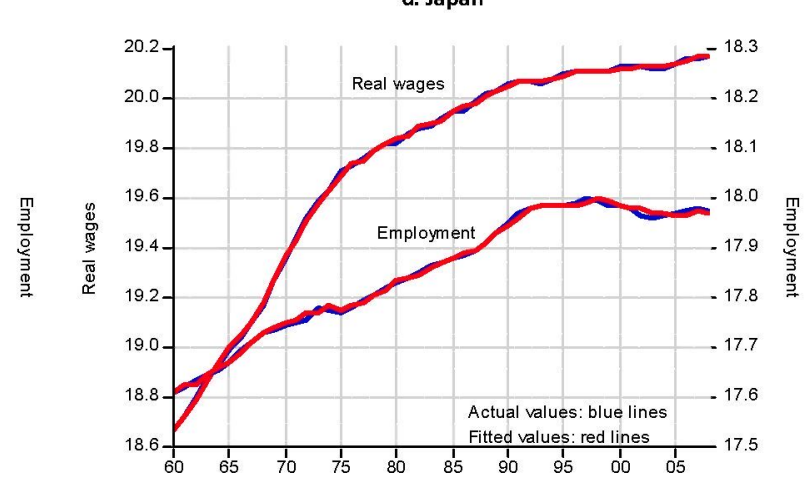

f. U.K.

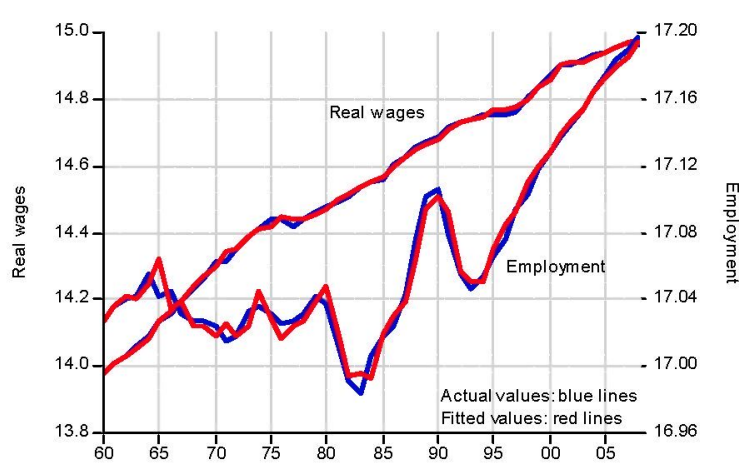


Figure A.2 France

a. Labour income share in the 1970 s (percent)

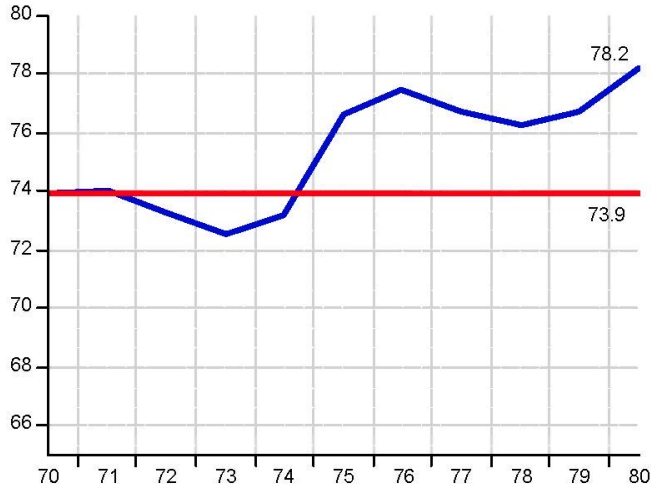

c. Labour income share in the 1980 s (per cent)

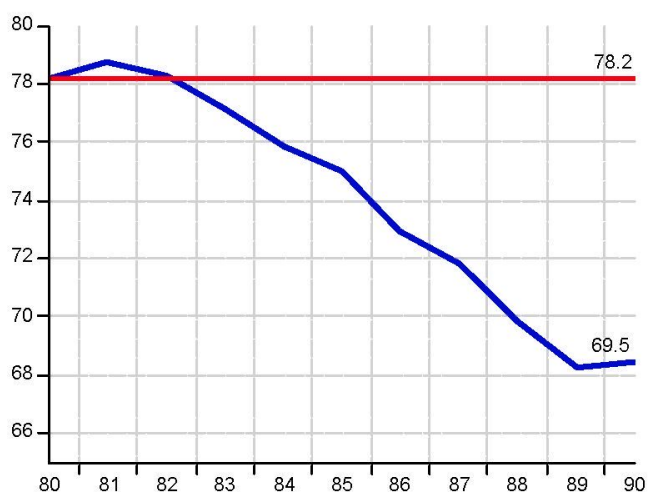

e. Labour income share in the 1990 s (percent)

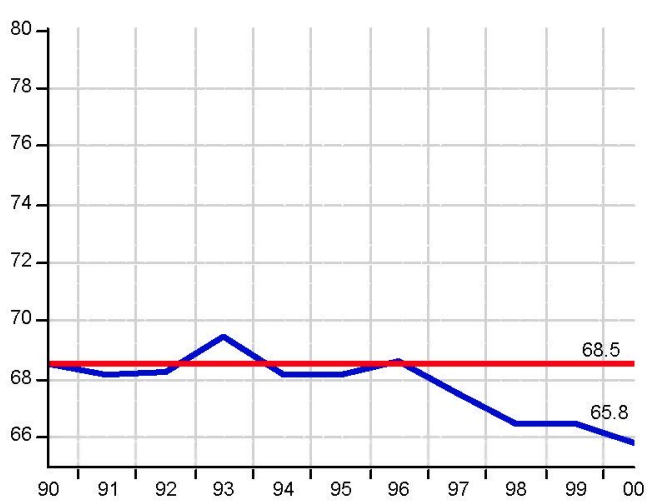

g. Labour income share in the 2000 s (percent)

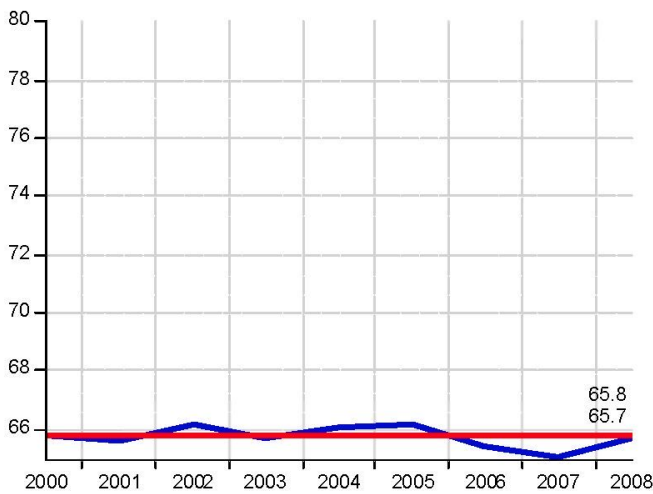

b. Employment in the 1970 s (millions)

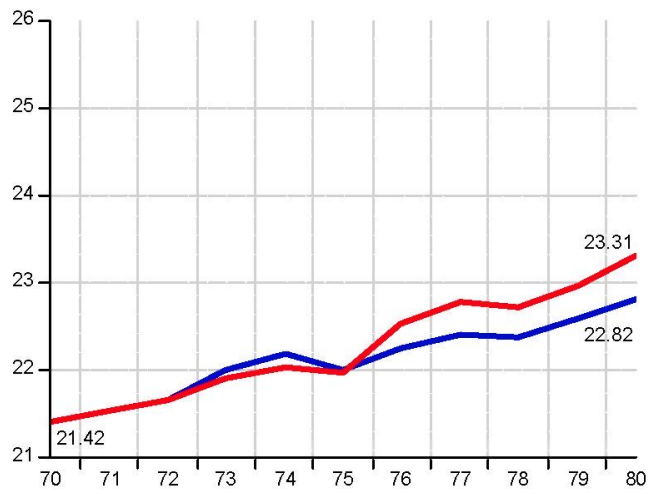

d. Employment in the 1980 s (millions)

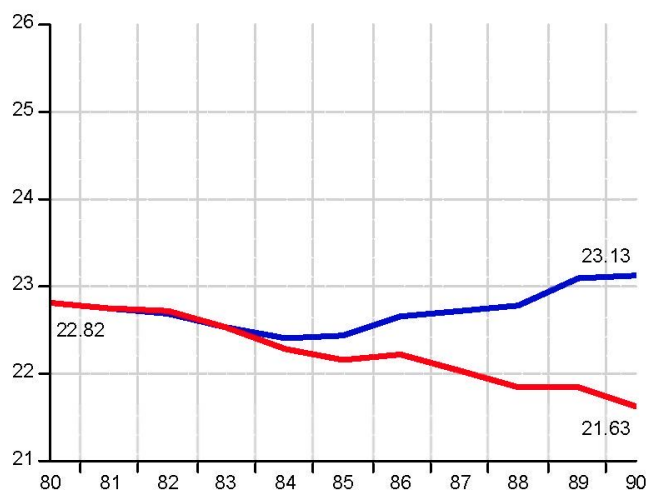

f. Employment in the 1990s (millions)

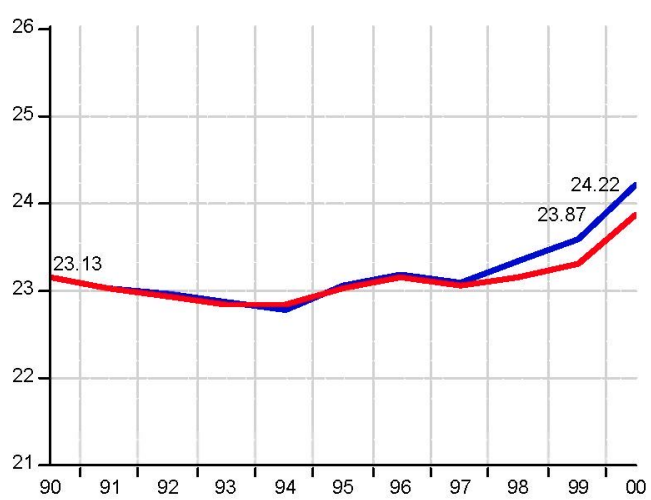

h. Employment in the 2000 s (millions)

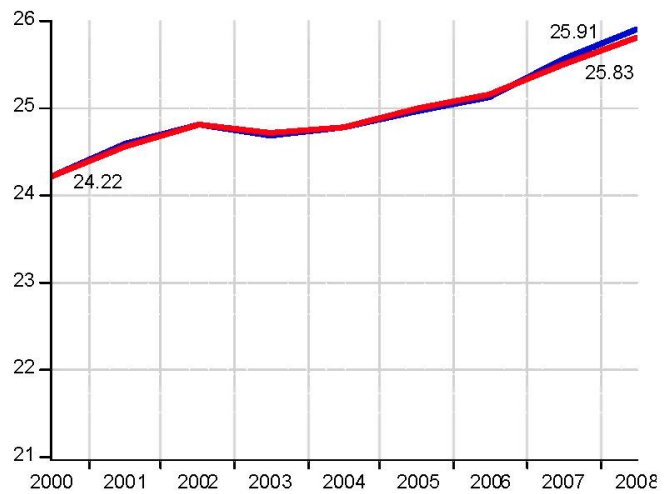


Figure A.3 Germany

a. La bour income share in the 1970 s (percent)

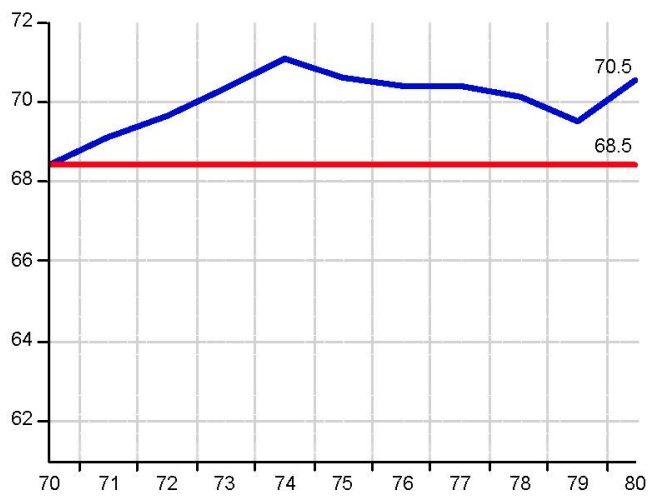

c. Labour income share in the 1980 s (percent)

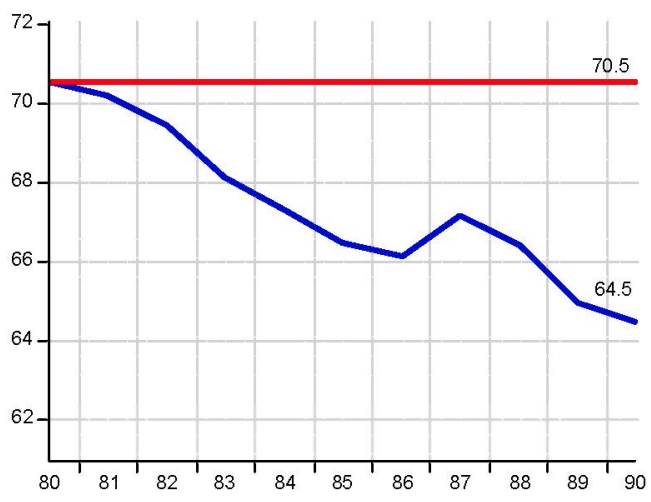

e. La bour income share in the 1990 s (percent)

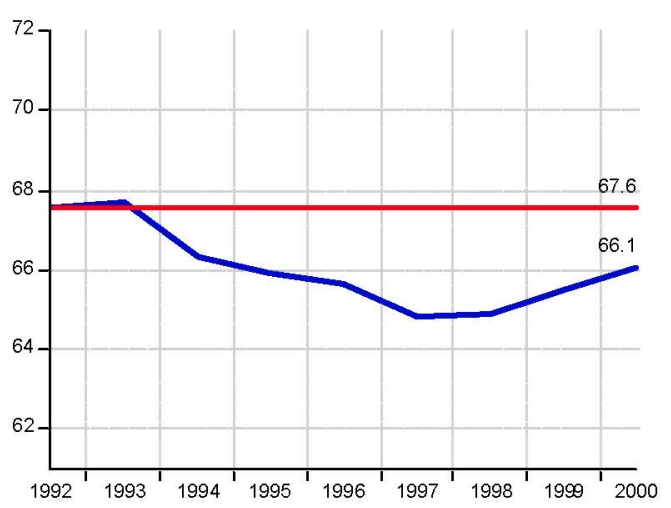

g. La bour income share in the 2000 s (percent)

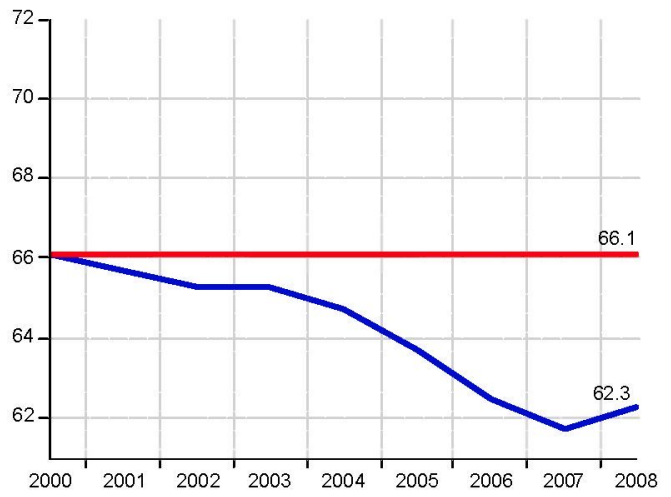

b. Employment in the 1970 s (millions)

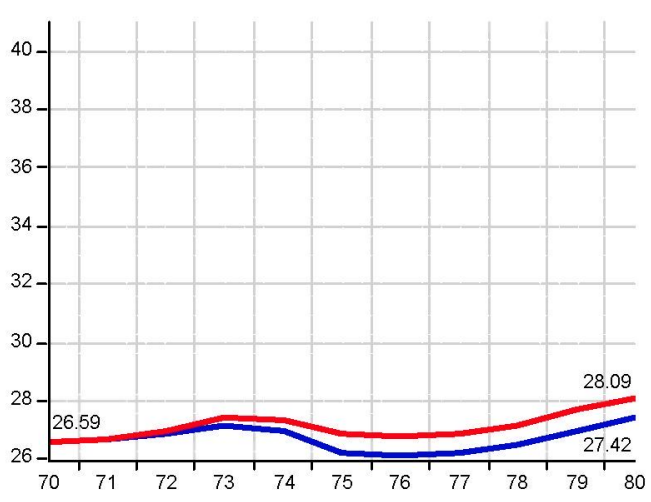

d. Employment in the 1980 s (millions)

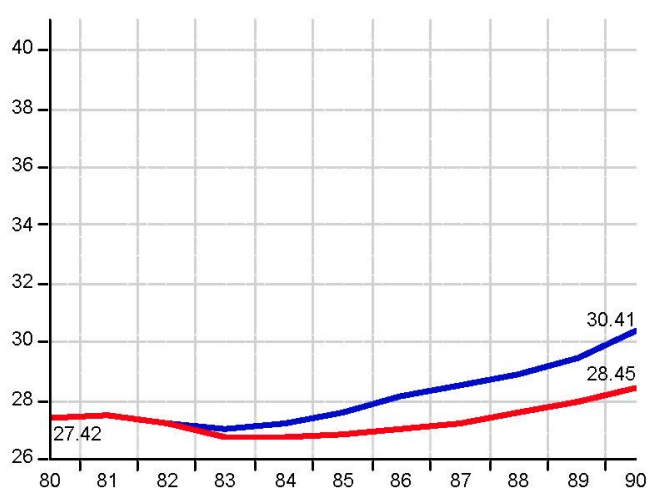

f. Employment in the 1990 s (millions)

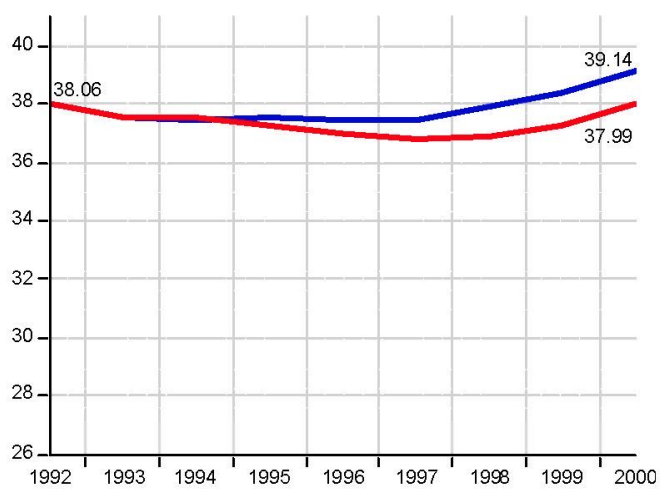

h. Employment in the 2000s (millions)

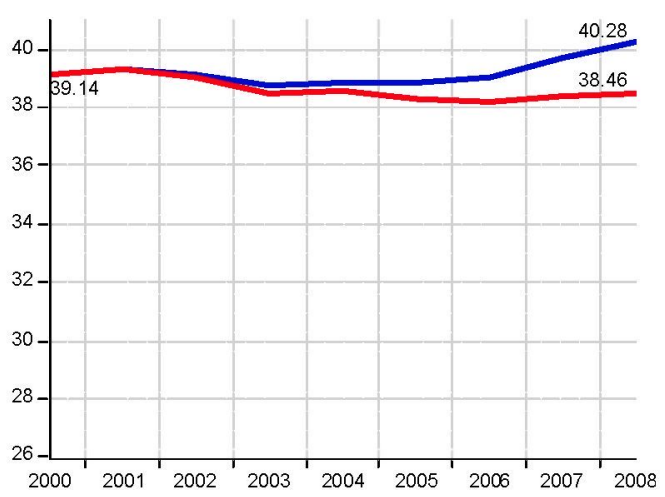


Figure A.4 Italy

a. La bour income share in the 1970 s (percent)

2. Employment in the 1970 s (millions)
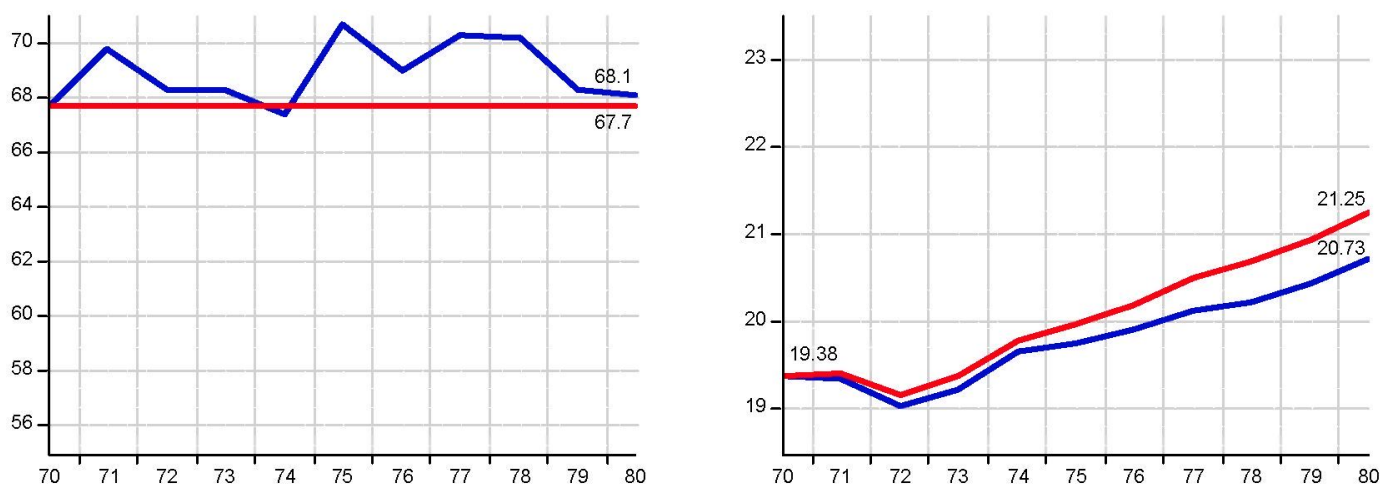

c. Labour income share in the 1980 s (percent)

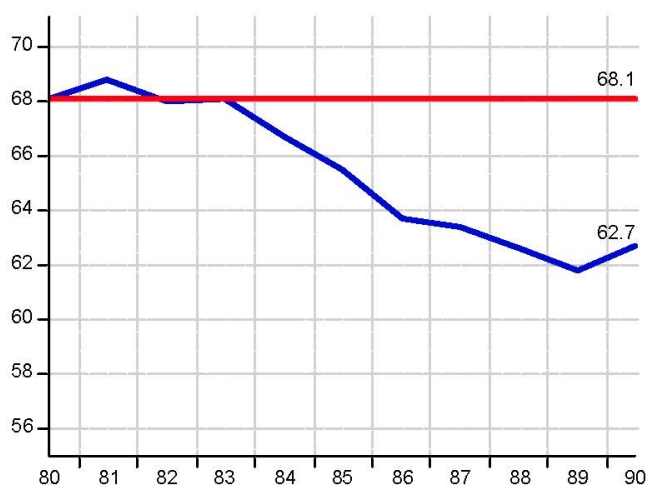

4. Employment in the 1980 s (millions)

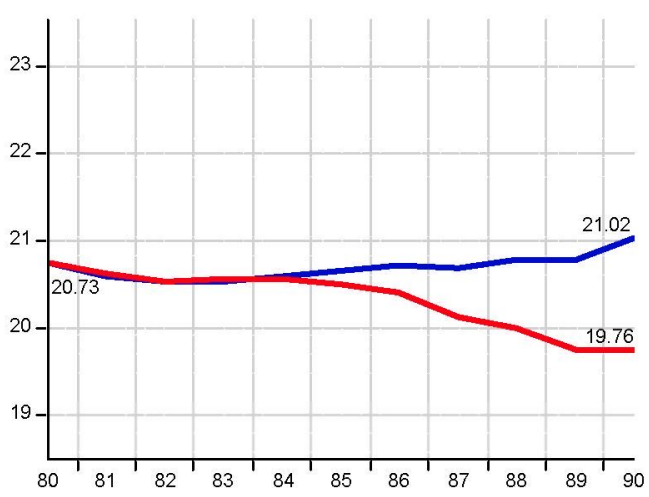

e. La bour income share in the 1990 s (percent)

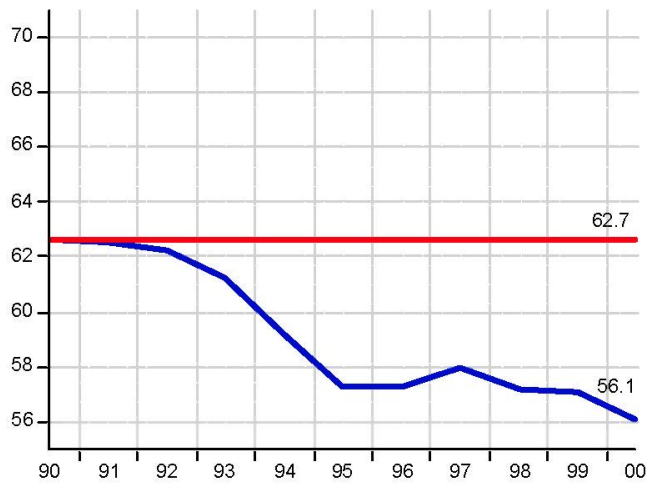

6. Employment in the 1990 s (millions)

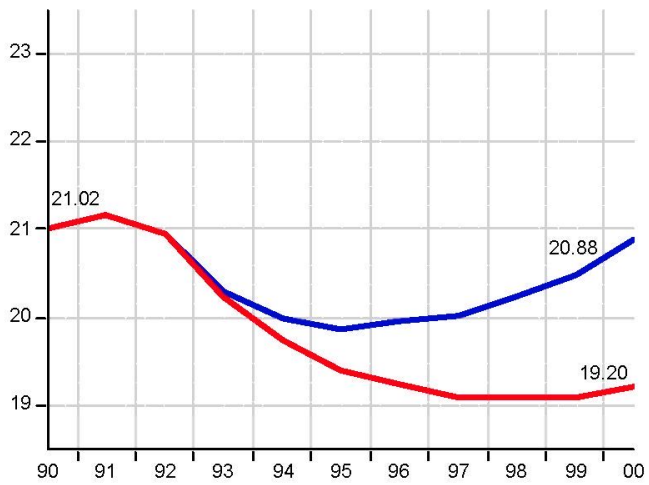

g. La bour income share in the 2000 s (percent)

8. Employment in the 2000s (millions)
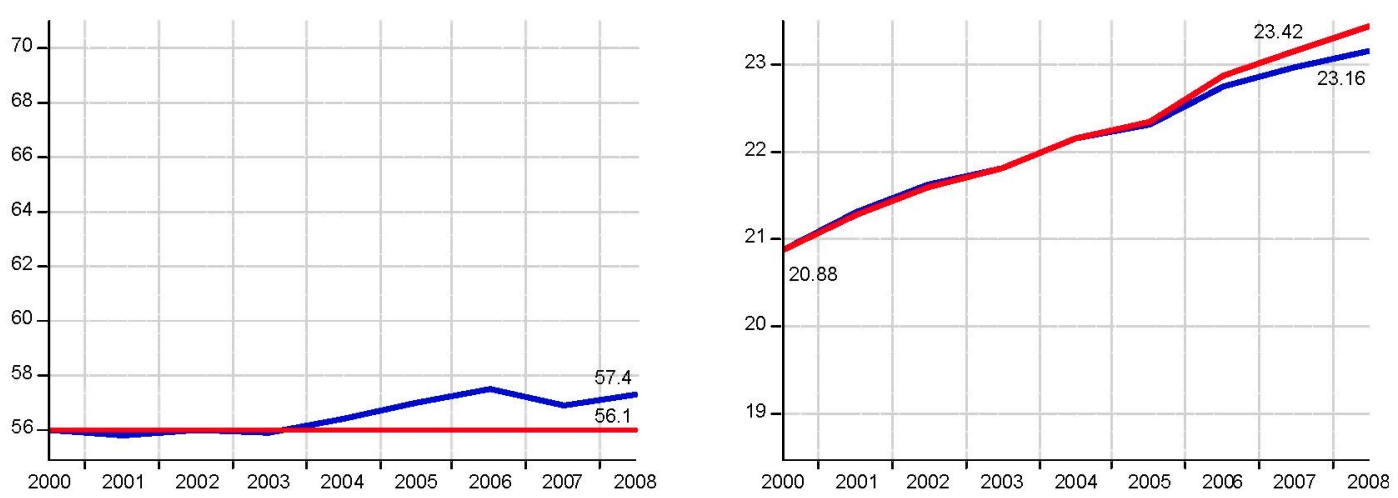
Figure A.5 Japan

a. La bour income share in the 1970 s (percent)

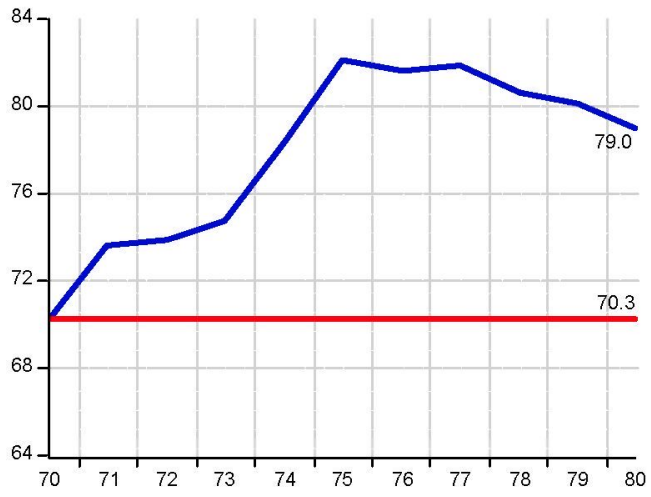

c. Labour income share in the 1980 s (percent)

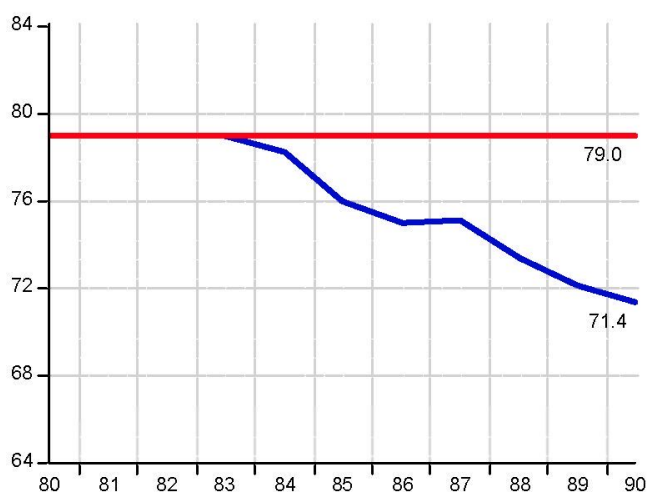

e. La bour income share in the 1990s (percent)

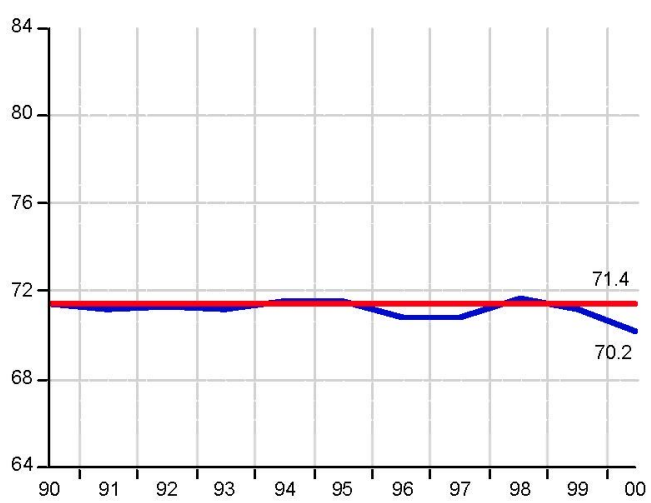

g. La bour income share in the 2000 s (percent)

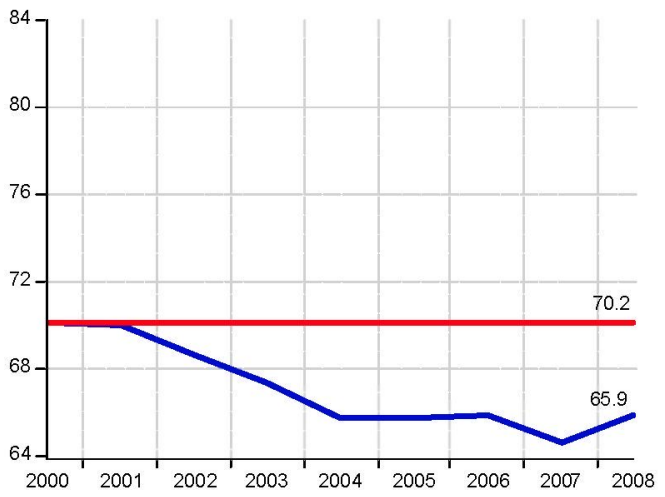

b. Employment in the 1970 s (millions)

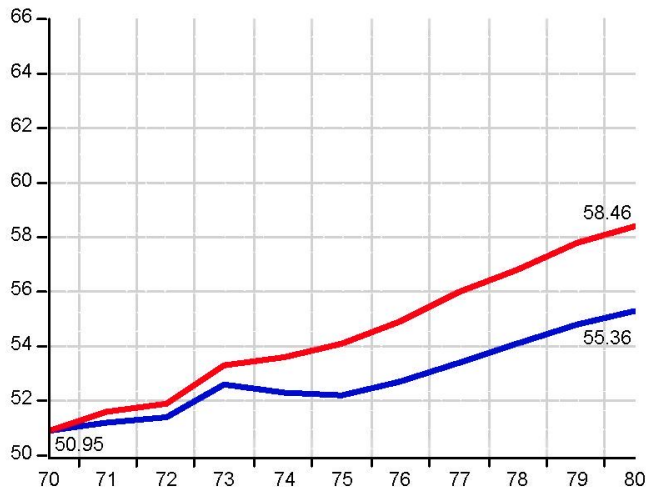

d. Employment in the 1980 s (millions)

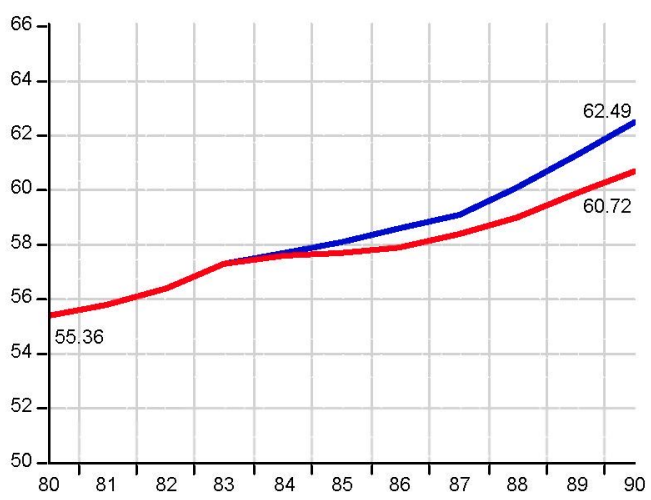

f. Employment in the 1990s (millions)

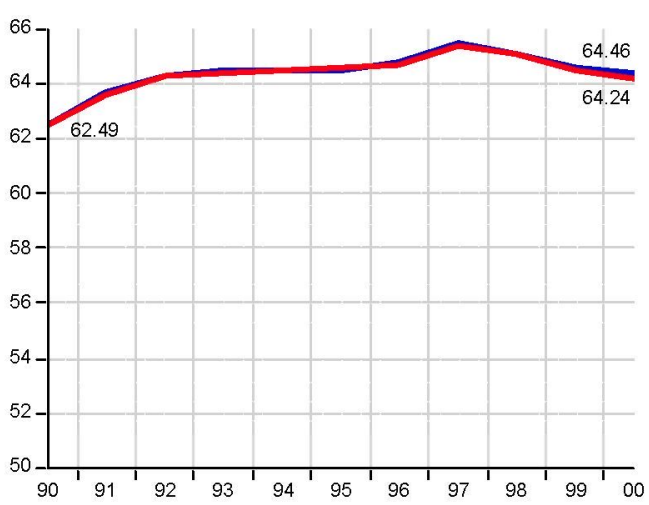

h. Employment in the 2000s (millions)

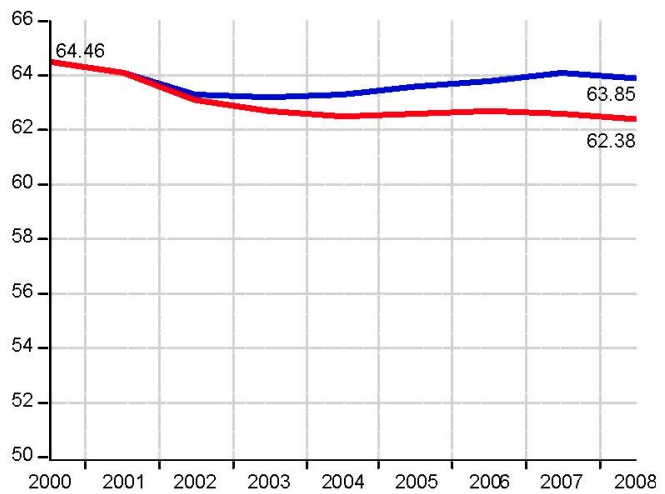


Figure A.6 Spain

a. La bour income share in the 1970s (percent)

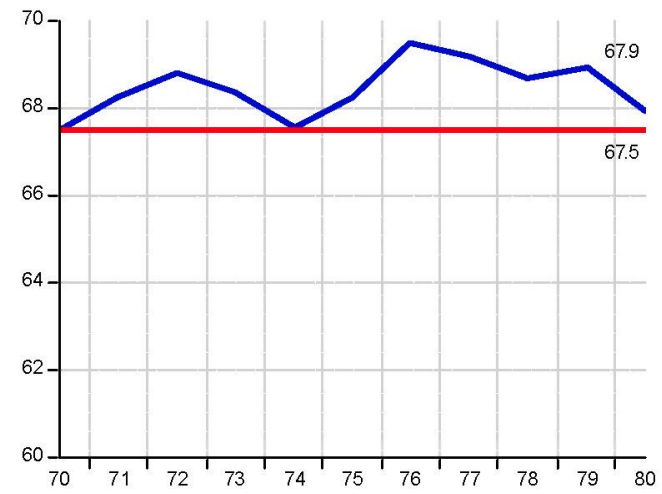

c. Labour income share in the 1980 s (per cent)

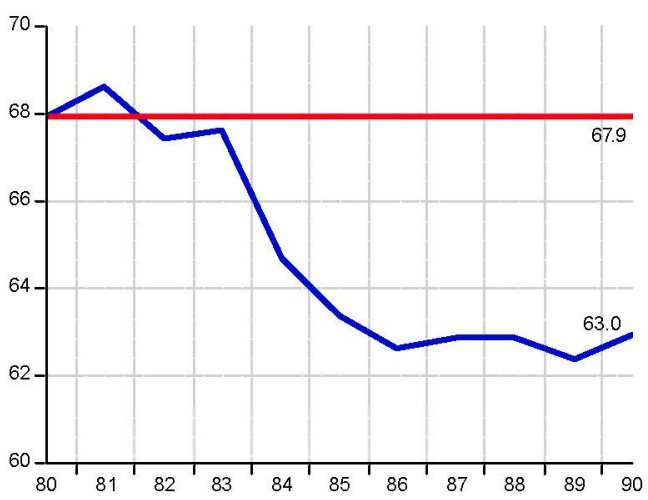

e. Labour income share in the 1990s (percent)

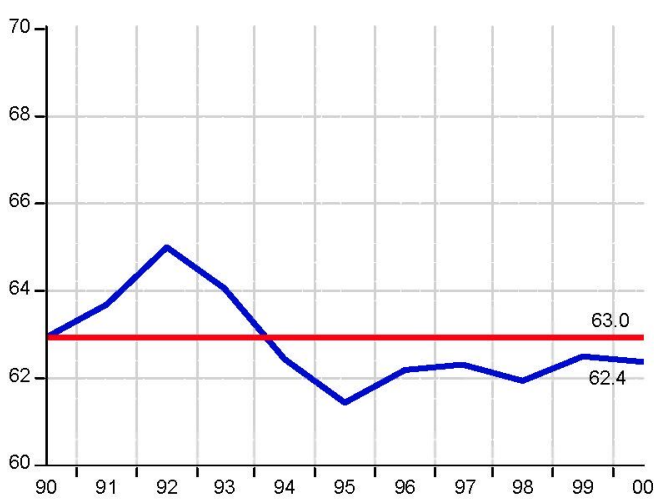

g. La bour income share in the 2000 s (percent)

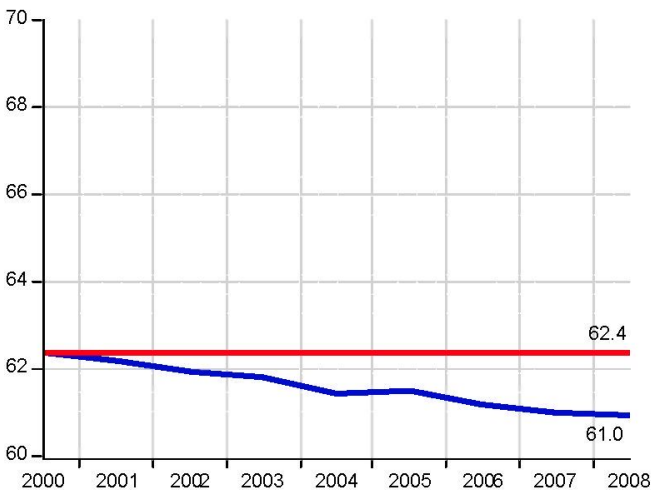

b. Employment in the 1970 s (millions)

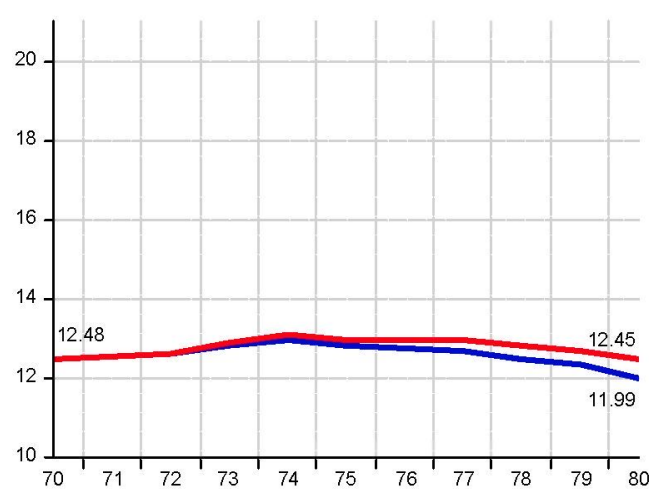

d. Employment in the 1980 s (millions)

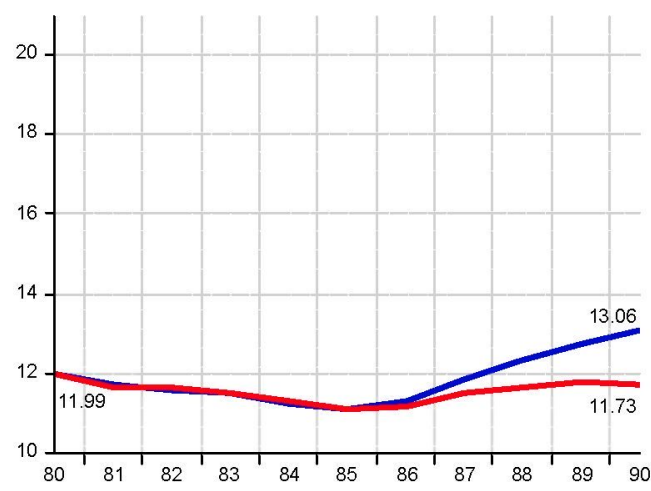

f. Employment in the 1990 s (millions)

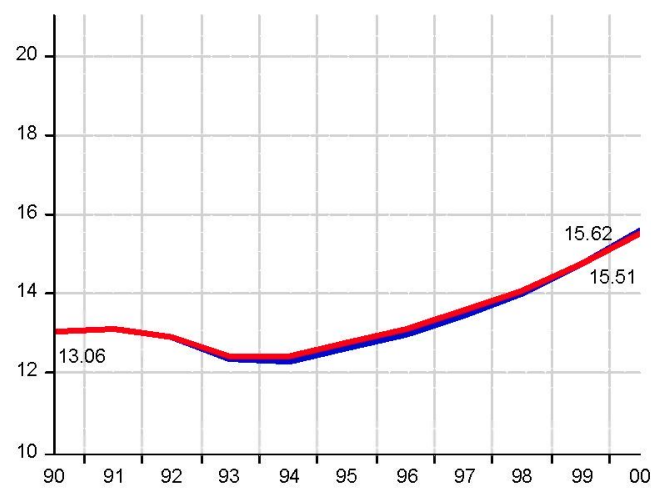

h. Employment in the 2000s (millions)

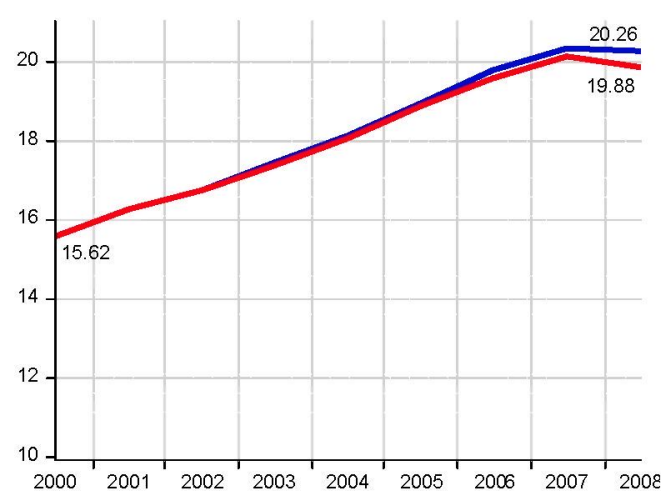


Figure A.7 UK

a. La bour income share in the 1970 s (percent)

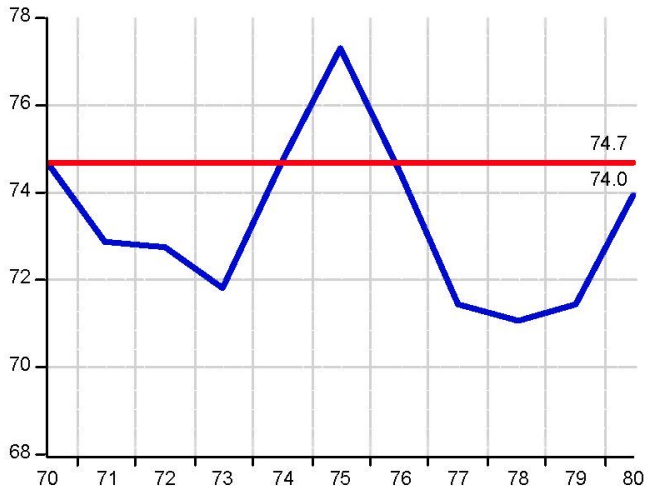

c. Labour income share in the 1980 s (percent)

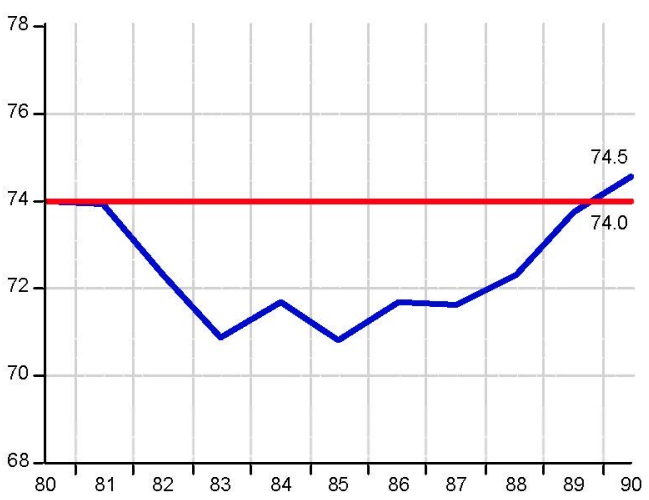

e. La bour income share in the 1990s (percent)

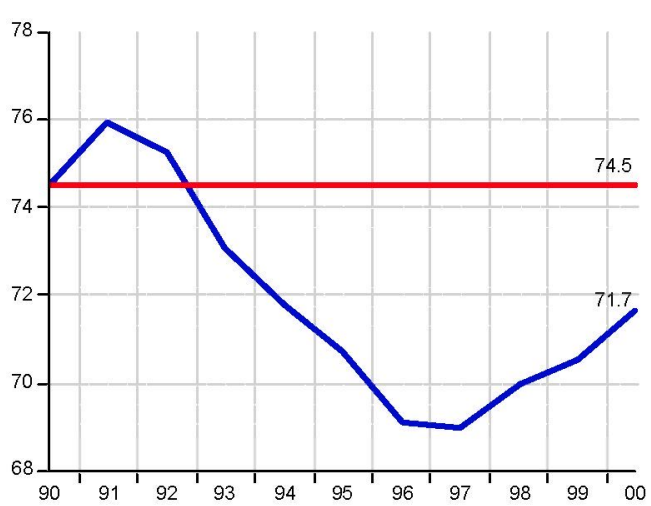

g. La bour income share in the 2000 s (percent)

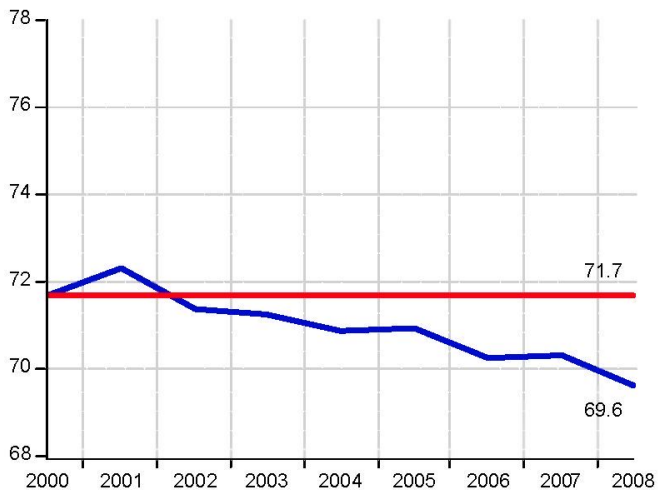

b. Employment in the 1970 s (millions)

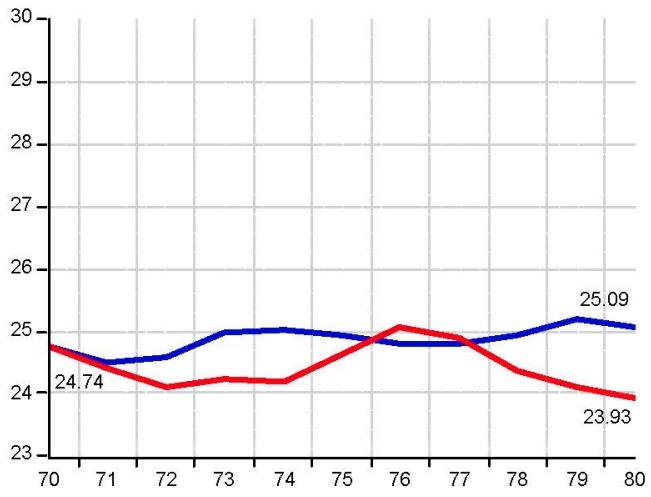

d. Employment in the 1980 s (millions)

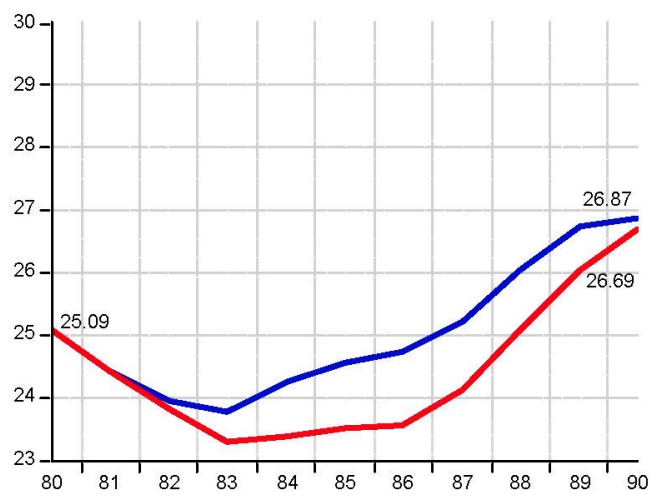

f. Employment in the 1990s (millions)

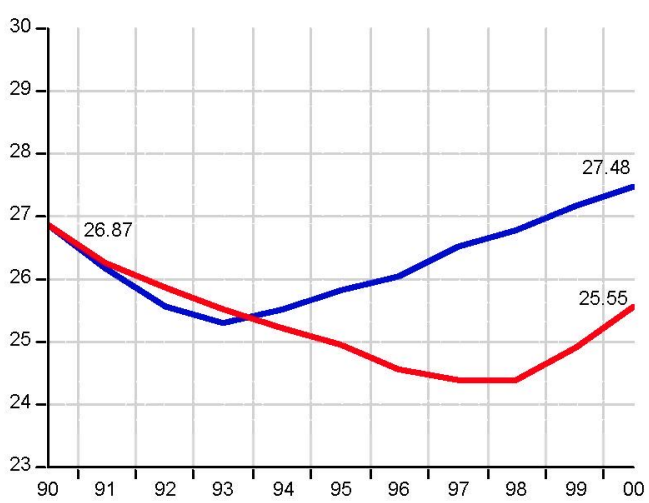

h. Employment in the 2000s (millions)

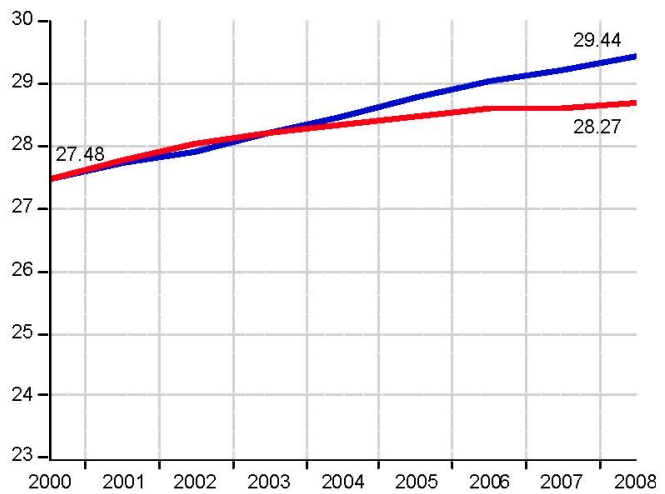


Figure A.8 US

a. La bour income share in the 1970 s (percent)

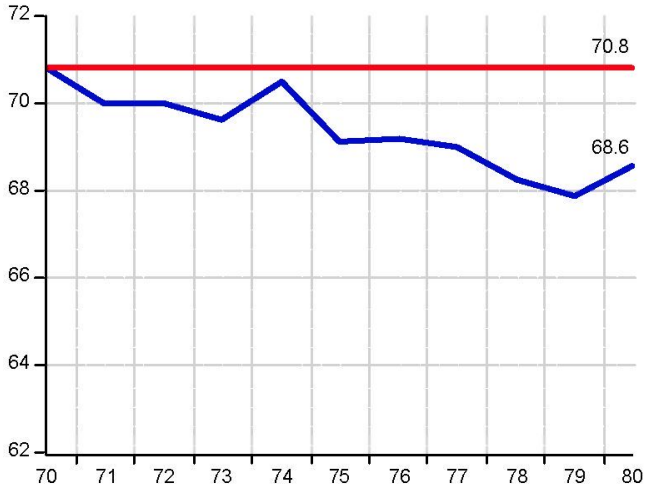

c. Labour income share in the 1980 s (percent)

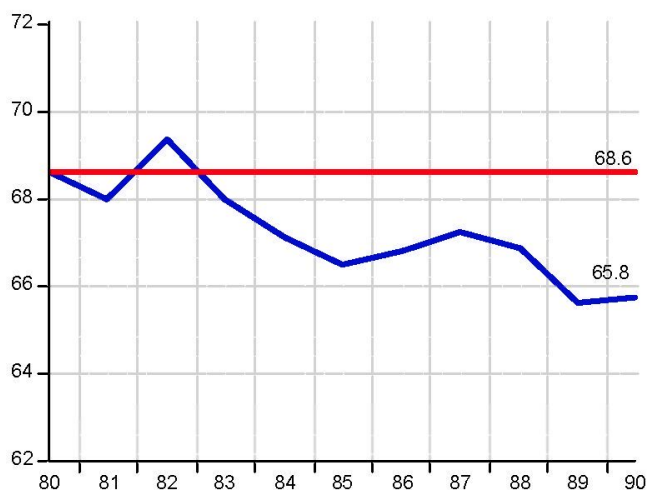

e. La bour income share in the 1990s (percent)

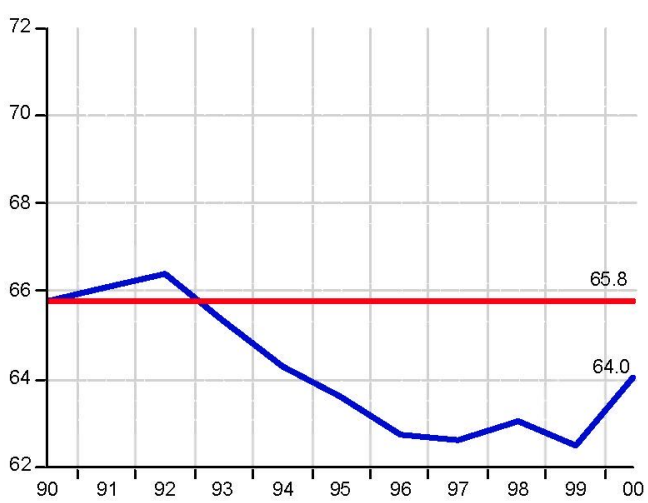

g. La bour income share in the 2000 s (percent)

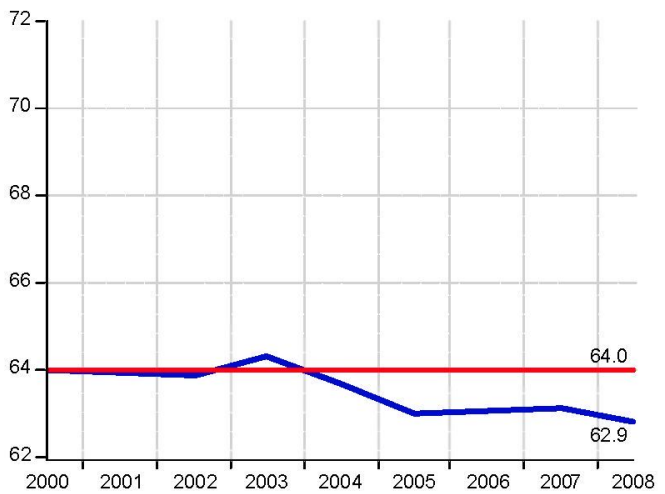

b. Employment in the 1970 s (millions)

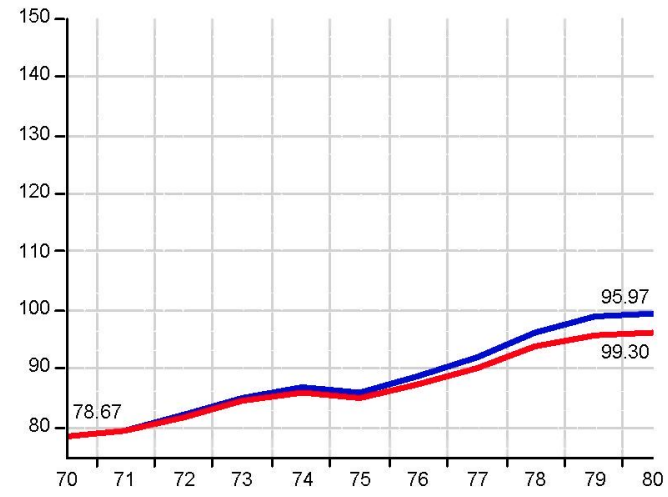

d. Employment in the 1980 s (millions)

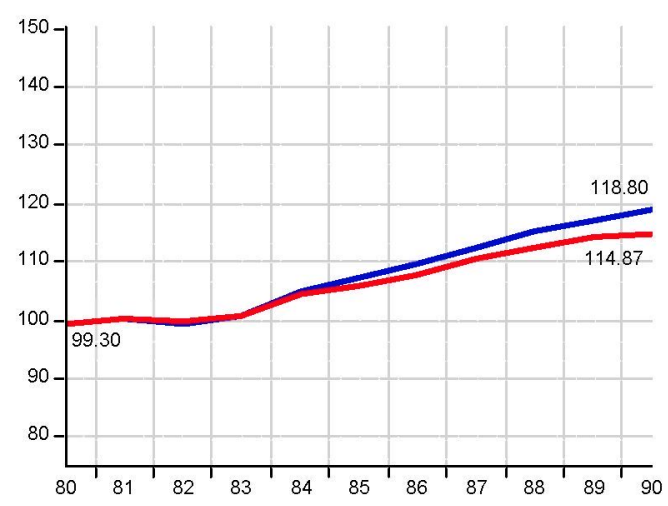

f. Employment in the 1990s (millions)

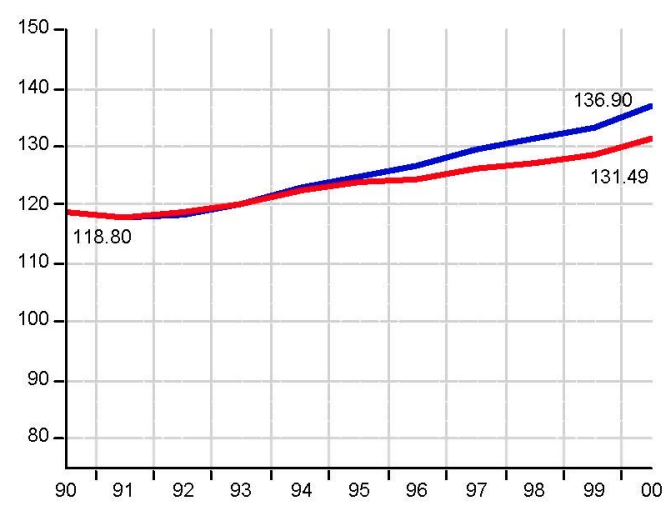

h. Employment in the 2000s (millions)

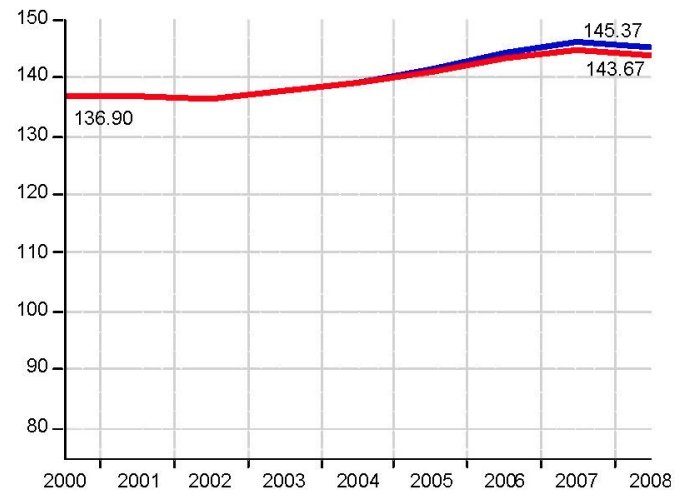

